\title{
Impact of a Stochastic Kinetic Energy Backscatter scheme across time-scales and resolutions
}

\author{
Claudio Sanchez, ${ }^{\mathrm{a} \star}$ Keith D. Williams, ${ }^{\mathrm{a}}$ Glenn Shutts ${ }^{\mathrm{a}}$ and Matthew Collins ${ }^{\mathrm{b}}$ \\ ${ }^{\mathrm{a}}$ Met Office, Exeter, UK \\ ${ }^{\mathrm{b}}$ College of Engineering, Mathematics and Physical Sciences, University of Exeter, UK
}

${ }^{\star}$ Correspondence to: C. Sanchez, Met Office, FitzRoy Road, Exeter, Devon EX1 3PB, UK. E-mail: claudio.sanchez@metoffice.gov.uk This article is published with the permission of the Controller of HMSO and the Queen's Printer for Scotland.

Stochastic physics is one of the preferred methods to represent model uncertainty in ensemble prediction systems of medium-range weather prediction and seasonal forecasting. These schemes increase the ensemble spread and improve probabilistic skill scores. However, little is known about how the stochastic perturbations interact with different atmospheric processes. In order to provide deeper insight into the impacts of stochastic physics on the representation of the atmosphere the stochastic kinetic energy backscatter (SKEB2) scheme has been used in the Met Office Unified Model (MetUM) across different time-scales. We use 'classic' verification techniques such as the Root Mean Error Square (RMSE) index in combination with novel 'object-oriented' verification metrics such as the Reading University Tracking system (RUTRACK) for extratropical cyclones. We find that the SKEB2 degrades the RMSE and Anomaly Correlation Coefficient (ACC) of individual short-range deterministic forecasts. On average the kinetic energy backscatter by the SKEB2 counteracts the excessive dissipation of extratropical cyclones, improving the model, but its forcing does not scale well across resolutions. Over the Tropics the SKEB2 improvements of the mean climatology and temporal variability are noteworthy, but driven by spurious Rossby waves. There are aspects of the SKEB2 that could be improved to create a more realistic stochastic representation of model uncertainty.

Key Words: $\quad$ stochastic physics; climate; storms

Received Received 29 May 2013; Revised Revised 18 December 2013; Accepted Accepted 6 January 2014; Published online in Wiley Online Library

\section{Introduction}

The spatial and temporal discretization of the equations that describe the atmosphere are associated with uncertainty on a wide range of time-scales from days to decades. The separation between resolved and unresolved processes is not observed in the atmosphere, in many cases the number of subgrid scale events per grid box is not large enough to permit the existence of a meaningful statistical equilibrium (Williams et al., 2005). The importance of subgrid variability and the nonlinear interactions between the unresolved and the resolved scales have been highlighted by the results from high-resolution atmospheric models able to resolve many of these subgrid processes, such as convection (Slingo and Palmer, 2011).

The atmospheric science community has developed tools to provide an estimate of the uncertainty in weather forecasts and climate projections produced by these limitations. Probably the best known of these is the ensemble prediction system (EPS), where a collection of forecasts for a given date is utilized to provide the probability of different outcomes. The different forecasts or members of the ensemble are designed to provide a probable value of an atmospheric variable rather than the evolution of the more likely state (Teixeira, 2007). To achieve this goal, Palmer (2001) proposed to stochastically simulate some processes that were missing or poorly simulated by the model.

Stochastic physics schemes are widely used in state-of-the art EPSs to produce probabilistic forecasts from days to seasons. They use techniques such as adding a stochastic perturbation to the parametrization tendencies, such as the stochastically perturbed parametrization of tendencies (SPPT) scheme (Buizza et al., 1999; Palmer et al., 2009) or adding a stochastic element inside the parametrization (Plant and Craig, 2008; Eckermann, 2011; Bengtsson et al., 2013). Another idea that has been adopted by many EPSs is to backscatter kinetic energy due to missing or highly diffused processes. This has been developed in the following schemes: cellular automata stochastic backscatter (CASB) (Shutts, 2005) for the integrated forecast system (IFS) of the European Centre for Medium- range Weather Forecast (ECMWF); the stochastic kinetic energy backscatter (SKEB2) scheme (Tennant et al., 2011) for the Met Office global and regional EPS (MOGREPS). Many of the schemes described above improve the probabilistic skill of various EPSs (Buizza et al., 1999; Berner et al., 2011, 2012; Tennant et al., 2011). Not only for short to medium weather forecasts ( $<15$ days), they have 
also proven skillful for monthly to seasonal scales (Weisheimer et al., 2011) and for seasonal to annual scales (Doblas-Reyes et al., 2009) in comparison with other methods to represent model error.

Stochastic physics also has the potential to improve the mean climate through the process of noise-induced drift. This phenomenon is well known in simple models where noise drives the model to abandon its preferred attractor and explore different regions of the phase space, creating a more realistic frequency of atmospheric regimes. Theoretically this should benefit a general circulation model (GCM), by increasing the ensemble spread and thus providing a better mean state of the model (Palmer, 2004), but given their complexity and nonlinearity, it is not yet clear how they improve the simulation of different atmospheric processes. Stochastic fluctuations to air-sea buoyancy fluxes can improve the century mean oceanic mixed-layer, depth, sea-surface temperature and atmospheric Hadley circulation (Williams et al., 2012). The IFS with CASB was able to simulate a better frequency of occurrence of weather regimes in the North Pacific (Jung et al., 2005), and improved tropical seasonal mean rainfall (Berner et al., 2008). The replacement of this scheme, the spectral backscatter scheme (SPBS) (Berner et al., 2009), improves the mean climate for the CY32R1 model cycle, outperforming the benefits of increasing horizontal resolution (Berner et al., 2012). However, in a more recent CY35R1 model cycle the performance of SPBS and SPPT produced a rather small improvement compared with the control model's systematic errors (Palmer et al., 2009). Lang et al. (2012) used a tropical cyclone tracking technique to understand whether the perturbations from the data assimilation and the different stochastic schemes were well tuned. They found that for the IFS, the SPBS and SPPT perturbations excite the growing modes of the tropical cyclone (TC) flow successfully. The spread in the TC tracks produced by the full perturbations (SPPT, SPBS plus data assimilation and a weak contribution from singular vectors) matches the TC track error of its ensemble mean, and the ensemble shows skill in capturing the spatial structure of the track errors.

In the present study, we analyse the impact of a stochastic kinetic energy backscatter scheme in a GCM. We aim to determine how realistic the behaviour of the model is with SKEB2 in comparison with a non-stochastic control run. We look at two different timescales: 5 day forecasts to determine how realistic the evolution of synoptic features is, as well as 20 year climate runs of the atmosphere to assess the impacts of SKEB2 perturbations in the mean climate and variability of the model. We make use of traditional verification techniques such as root mean square error (RMSE), anomaly correlation coefficient (ACC) and bias analysis, as well as a feature-based tracking of extratropical storms to determine the scheme's impact on midlatitude variability, we also analyse convectively coupled waves for their tropical variability.

The present formulation of kinetic energy backscatter schemes is fully stochastic, with perturbations acting across different spatial scales. The SPBS forces all wave numbers and the SKEB2 forcing pattern is built from wave number 5 to 60 . There has been recent research suggesting that backscatter is more effective and realistic through a deterministic parametrization acting at large scales (Shutts, 2013; Thuburn et al., 2013). Our evaluation of the present scheme leaves the deterministic/stochastic dilemma aside, although we are aware of the potential benefits that a combination of a deterministic baskcatter at large-scales and stochastic at short-scales could have.

The model, the stochastic physics scheme and the methodology used to evaluate the model are briefly described in section 2 , results from the 5 day forecasts are presented in section 3 , and results from 20 year climate runs are shown in section 4 . The article concludes with a summary and discussion of the results in section 5 , together with some suggestions on how to develop and evaluate stochastic physics.

\section{Model description and analysis methodology}

\subsection{The Met Office Unified Model}

The Met Office Unified Model (MetUM) has been developed since 1990 as a single model for seamless modelling from weather to climate time-scales (Cullen et al., 1993; Brown et al., 2012). In its current configuration, Global Atmosphere 3 (Walters et al., 2011), it uses the same model dynamics and physics settings across different resolutions and time-scales. This makes MetUM suitable to explore the impact of spin-up effects of any change in the model configuration across a variety of time-scales and resolutions (Senior et al., 2011; Hoskins, 2012).

The MetUM is a fully non-hydrostatic gridpoint model with a semi-Lagrangian advection scheme (Davies et al., 2005). The horizontal resolution is defined as the number of nodes with the shortest zonal wave number, allowing approximate comparison with the truncation scale. In order to make the grid box isotropic in the mid-latitudes, the number of grid points north-south is $3 N / 2+1$. The different horizontal resolutions used in this study are: N320 (approximately $40 \mathrm{~km}$ in the midlatitudes), N216 $(\sim 60 \mathrm{~km})$ and N96 $(\sim 135 \mathrm{~km})$.

\subsection{The stochastic kinetic energy backscatter scheme}

The SKEB2 scheme is based on the kinetic energy backscatter idea proposed by Shutts (2005), and it is currently operational in the 15 days MOGREPS (Bowler et al., 2008; Tennant et al., 2011) and in the seasonal model Global Seasonal (Glosea4; Arribas et al., 2011) systems. The SKEB2 scheme aims to backscatter energy lost by numerical dissipation, the energy lost from interpolation to the departure point in the semi-Lagrangian scheme (Sanchez et al., 2012), and small-scale eddy dissipation around convective updraughts. Unlike other stochastic kinetic energy backscatter schemes (e.g. IFS SKEB), it does not include the orography component.

A comprehensive formulation of the SKEB2 scheme is provided by Tennant et al. (2011), but a brief description is given here. The scheme's forcing is targeted onto winds' stream function (rotational part) and velocity potential (divergent). It is the projection $\hat{F}_{\Psi}$ of a stochastic forcing field $F_{\psi}$ on an estimate of the energy dissipated at the current time step, defined as dissipation function $D_{\mathrm{TOT}}$ : as shown in Eq. (1), where $\lambda$ is longitude, $\mu$ latitude, $b_{\mathrm{R}}$ is the backscatter ratio, an amplitude factor to modulate the forcing of the scheme, and $B_{\mathrm{TOT}}$ is the globally uniform energy input rate.

$$
\hat{F}_{\Psi}(\lambda, \mu, z)=\sqrt{\left(b_{R} \frac{D_{T O T}(\lambda, \mu, z)}{B_{T O T}}\right)} F_{\psi}
$$

The SKEB2 forcing field $F_{\psi}$ or forcing pattern is governed by a spectral expansion of the spherical harmonics, the coefficients of which evolve stochastically in time following a first-order autoregressive process, and in which the temporal and spatial scales are autocorrelated. The SKEB2's power spectrum is assumed to be a power law, the exponent of which is derived from coarsegrained studies (Shutts and Palmer, 2007). The dissipation rate is the sum of the numerical dissipation rate, which uses the Smagorinsky closure to estimate the loss of energy due to the interpolation to the departure point, and the convective rate, which relates to the vertical gradient of the parametrized convective mass flux.

\subsection{Methodology}

In the present study we have combined results from two different timescales: a set of 200 five-day forecasts for the summer and winter of 2008-2011 using different horizontal resolutions - N320, N216 and N96; plus N96 climate simulations 
of 20 years, with prescribed sea ice and SSTs following the Atmosphere Model Intercomparison Project (AMIP; Gates et al., 1999) experimental design. In order to understand whether the SKEB2 impact is adequate, we amplify the forcing by increasing the backscatter ratio $b_{\mathrm{R}}$ parameter (Eq. (1)) from its default value of 0.0275 to $0.1,0.2$ and 0.3 in our N96 experiments. Berner et al. (2009) found that this default value was optimal to produce enough ensemble spread and a realistic kinetic energy spectra for the IFS at a horizontal resolution of $\mathrm{T}_{\mathrm{L}} 511$ (approximately equivalent to N216) against its own analysis.

In order to assess SKEB2's capacity to generate spread at climate scales and thus be considered as a useful tool to estimate model uncertainty for future climate projections, we run an ensemble of five identical climate simulations of MetUM with the SKEB2 scheme. Another three simulations of the SKEB2 scheme with $b_{\mathrm{R}}=0.1$ are added to the ensemble. This ensemble is compared with the climate model's predecessor, the Hadley Centre Global Environment Model v2 (HadGEM2) (Collins et al., 2011): the HadGEM2 ensemble consist of seven members with initial perturbations to soil variables and two members swap their soil variables at the start of each month.

Forecasts are compared with the ECMWF analysis and climate runs are compared against the ECMWF Interim Reanalysis (ERAInterim; Dee et al., 2011) and Modern Era Retrospective analysis for Research and Applications (MERRA) (Bosilovich et al., 2008). We also use the observed radiative flux climatology provided by Clouds and the Earth's Radiant Energy System CERES (Wielicki et al., 1996) to compare against model radiative fields, and the Global Precipitation Climate Project (GPCP) (Adler et al., 2003) for precipitation.

The SKEB2 scheme forces the stream function and velocity potential of the winds, so we assess how the model simulates winds at two different levels, $850 \mathrm{hPa}$, where cyclonic activity is at its peak, and $250 \mathrm{hPa}$, where the jet stream flows.

\subsection{Extratropical cyclone tracking}

Weather in the midlatitudes is driven by synoptic-scale cyclones, which control winds, cloudiness and precipitation. At longer time-scales these cyclones are equally important because they transport heat, momentum and water vapour from the Equator to the poles. A tool to diagnose cyclones is the Reading University tracking (RUTRACK) algorithm (Hodges, 1994, 1995, 1996) This algorithm filters and discards the large-scale (wave number $<5$ ) and mesoscale (wave number $>42$ ) motions from a relative vorticity field at $850 \mathrm{hPa}$, then maxima and minima above the threshold of $10^{-5} \mathrm{~s}^{-1}$ are tracked from a six-hourly interval dataset by computing the minima of the field cost function. The last constraint is that a cyclone must last at least 2 days and travel farther than $1000 \mathrm{~km}$; the vorticity field at $850 \mathrm{hPa}$ is chosen because it can show storms in their early development, whereas other metrics such as pressure at mean sea level cannot (Hoskins and Hodges, 2002). A number of statistics of the properties of cyclones, such as cyclone intensity or maximum of relative vorticity, areas of genesis or lysis, speed and density can be easily obtained.

The RUTRACK algorithm has been further developed into an object-oriented verification system that matches storms from analyses and models (Froude et al., 2007). The technique pairs a simulated and observed storm if these are closer than four geodesical degrees during the first day of the storm and they share more than $70 \%$ of their temporal points. This technique was used by Froude $(2010,2011)$ to diagnose the representation of extratropical cyclones across a wide range of EPS for both hemispheres. This research found that the mean of the tracks of all ensemble members provides an advantage over the unperturbed member for the intensity of cyclones, and more importantly to us, that EPS, which perturbs their forecast model physics, had the highest performance in terms of intensity: differences were minimal for errors in the location of cyclones.

\subsection{Convectively coupled equatorial waves}

A substantial fraction of the tropical variability at time-scales shorter than 30 days is organized by waves, coupled to convection, that move eastward or westward along the Equator. These waves are know as convectively coupled equatorial waves (CCEW) and they are fundamental dynamical components of the tropical atmosphere (Kiladis et al., 2009, and references therein). The basic structure and dispersive characteristics of CCEWs are described by the wave solutions of the shallow-water equations. These equations assume a dry atmosphere with no vertical structure, which nevertheless is a realistic approximation because there are spectral peaks from real observations over the dispersion relation curves for the solutions of the equatorial waves.

In order to evaluate the capacity of the model to represent the dispersive relationship of CCEWs, we employ the backgroundremoved power spectra of winds at $850 \mathrm{hPa}$ as done by Wheeler and Kiladis (1999). The longitudinal and temporal nodes of variability are obtained by performing a double Fourier transform in space and time over the meridional mean of a tropical field. The meridional mean can be symmetric, the sum of values from all latitudes, or antisymmetric, the sum of values in the Northern Hemispere $(\mathrm{NH})$ latitudes minus values in the Southern Hemisphere ( $\mathrm{SH}$ ) latitudes. The wavenumber-frequency field is obscured by the red noise present, so a background power spectrum is built by averaging the power of the symmetric and antisymmetric component and smoothing 10 times with a 1-2-1 filter in frequency and wave number. Dividing the raw individual power spectra by the background power spectra yields the classic plot of background-removed power spectra, where the dispersion curves are clearly seen (see Figures 12(f) and 13(f)).

The CCEWs help the propagation of the Madden-Julian Oscillation (MJO), the main mode of variability in the Tropics (Zhang et al., 2005). To obtain the background removed power spectra and other MJO diagnostics we make use of some of the MJO task-force diagnostics (Waliser et al., 2008).

\section{Results for five-day Weather forecasts}

\subsection{Forecast skill scores}

We compute the RMSE for a set of 200 deterministic forecasts across different resolutions with and without the SKEB2 scheme, for winds at 850 and $250 \mathrm{hPa}$. We analyse three different regions: Northern Hemisphere $\left(90^{\circ} \mathrm{N}-20^{\circ} \mathrm{N}\right)$, Tropics $\left(20^{\circ} \mathrm{N}-20^{\circ} \mathrm{S}\right)$ and Southern Hemisphere $\left(20^{\circ} \mathrm{S}-90^{\circ} \mathrm{S}\right)$. The ratio between the averaged SKEB2 RMSE and control RMSE is always $>1$, as shown in Figure 1, thus the SKEB2 sheme produces a detrimental increase of RMSE for all forecast lead-times, regions, levels and resolutions. Errors at $850 \mathrm{hPa}$ are higher than at $250 \mathrm{hPa}$ and they peak at day two of the forecast. The RMSE increases with resolution because the sharper gradients around features such as cyclones or fronts, which are located in the wrong place, lead to higher RMSE - the 'double penalty' argument.

If we increase the SKEB2's amplitude for the low-resolution version, the RMSE increases dramatically, as shown in Figure 2 (up to $35 \%$ for $b_{\mathrm{R}}=0.3$ ), with the same pattern: i.e., the increase in the RMSE ratio at level $850 \mathrm{hPa}$ is higher than at $250 \mathrm{hPa}$ and errors peak at day two. The higher the SKEB2 forcing the more severe is the damage to the forecast skill in terms of point-by-point differences for winds. The ACC for summer and winter decreases when the SKEB2 amplitude increases (Table 1), implying that the RMSEs are not fully explained by the double-penalty argument.

Despite the degradation of forecast skill scores, the SKEB2 scheme improves the mean bias of the model at N96, as shown in Figure 3. Winds at $850 \mathrm{hPa}$ are too weak in the midlatitudes (Figure 3(a)), mainly because of the numerical diffusion, which diffuses synoptic-scale eddies thereby slowing their spin, as well as the lack of upscaling kinetic energy from small-scale buoyant convective events. When we increase SKEB2's amplitude 


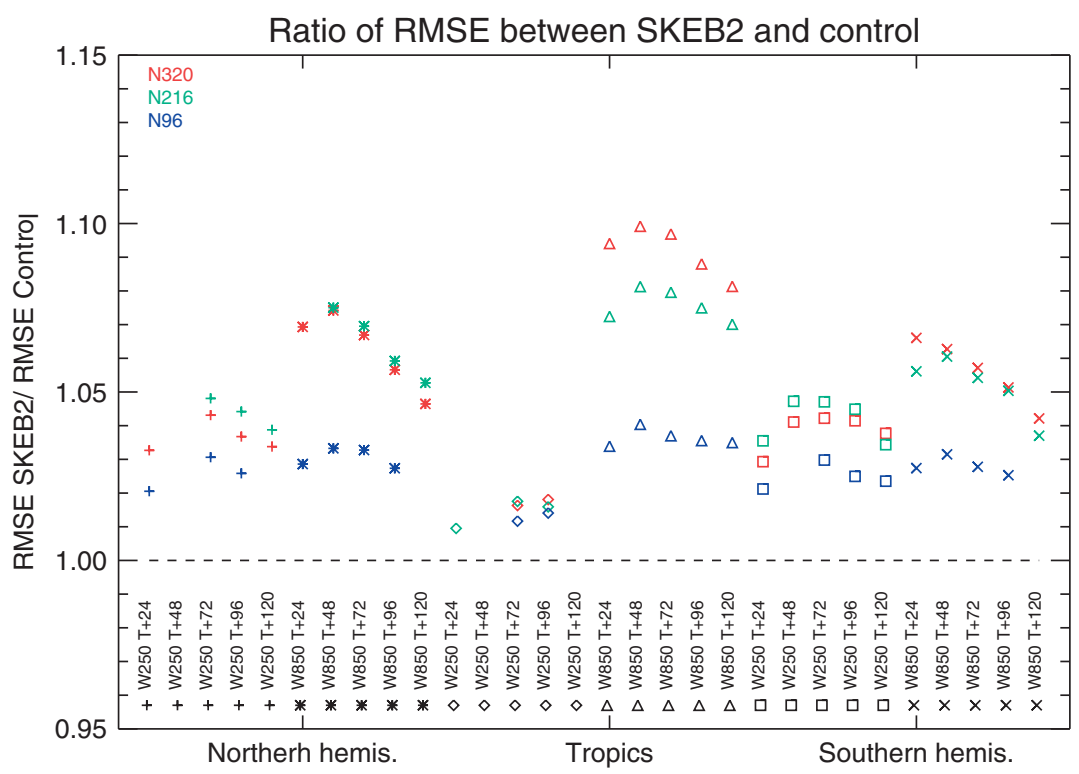

Figure 1. Ratio of root mean square of the SKEB2 scheme and control for several forecast times. Pluses denote winds at $250 \mathrm{hPa}$ and asterisks winds at $850 \mathrm{hPa}$ for the Northern Hemisphere $\left(20^{\circ} \mathrm{N}-90^{\circ} \mathrm{N}\right)$, diamonds winds at $250 \mathrm{hPa}$ and triangles at $850 \mathrm{hPa}$ for the Tropics $\left(20^{\circ} \mathrm{N}-20^{\circ} \mathrm{S}\right)$, squares winds at $250 \mathrm{hPa}$ and crosses winds at $850 \mathrm{hPa}$ for Southern Hemisphere $\left(20^{\circ} \mathrm{S}-90^{\circ} \mathrm{S}\right)$. Red is for the N320 SKEB2/control ratio, green for N216 and blue for N96. A set of 200 five- day forecasts for summer and winter from 2008 to 2012 have been compared against ECMWF analysis. Only results above the $95 \%$ of statistical significance are shown. This figure is available in colour online at wileyonlinelibrary.com/journal/qj

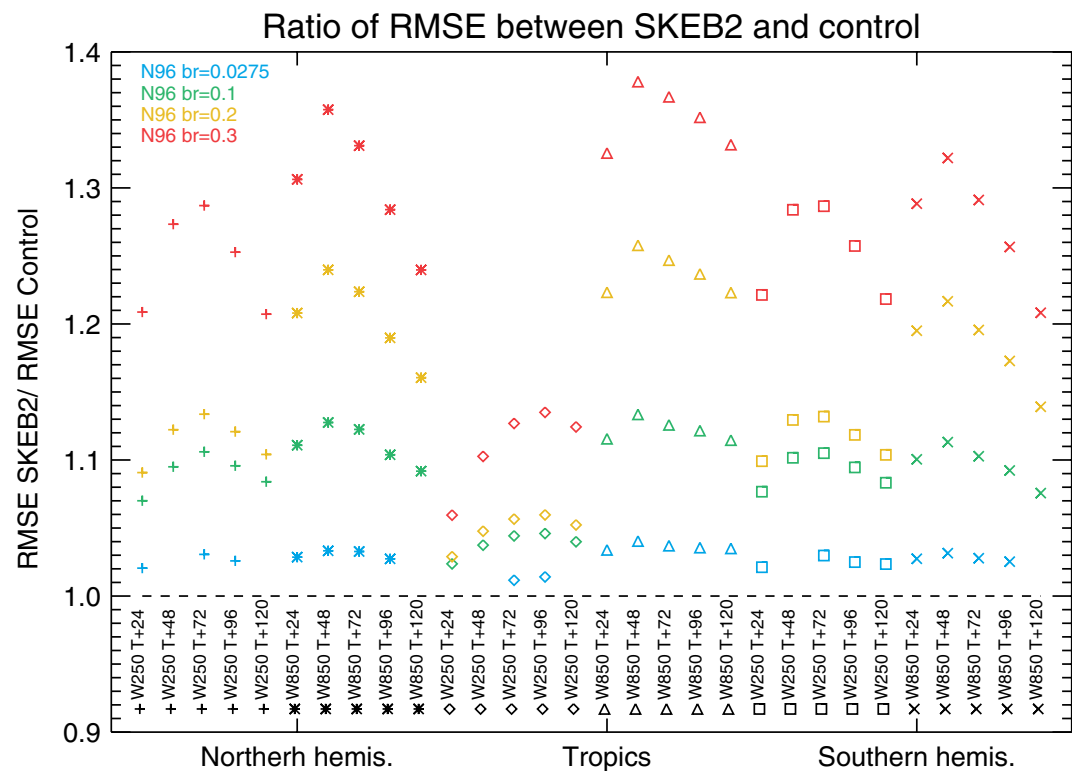

Figure 2. Same as Figure 1 but for different SKEB2 backscatter ratios ' $b_{\mathrm{R}}$ ' at N96. Pale blue is for the ratio of the SKEB2 scheme with the default backscatter ratio (equal to 0.0275 ) and control; green for $b_{\mathrm{R}}=0.1$; yellow for $b_{\mathrm{R}}=0.2$ and red for $b_{\mathrm{R}}=0.3$. This figure is available in colour online at wileyonlinelibrary.com/journal/qj

Table 1. Global average anomaly correlation coefficient for various simulations and seasons at $\mathrm{T}+120 \mathrm{~h}$. Computed from 100 forecast 3 day lagged for 4 years.

\begin{tabular}{lcc}
\hline Experiment & December-February & June-August \\
\hline Control & 0.50 & 0.47 \\
SKEB2 $b_{\mathrm{R}}=0.0275$ & 0.47 & 0.45 \\
SKEB2 $b_{\mathrm{R}}=0.1$ & 0.42 & 0.38 \\
SKEB2 $b_{\mathrm{R}}=0.2$ & 0.36 & 0.33 \\
SKEB2 $b_{\mathrm{R}}=0.3$ & 0.31 & 0.27 \\
\hline
\end{tabular}

the winds become stronger, which removes the biases in the midlatitudes, but at high $b_{\mathrm{R}}$ it creates winds in the tropical West Pacific and Maritime continent that are too strong, which indicates that perhaps the kinetic energy backscattered by this scheme at this amplitude is higher than the energy lost or not represented by the model. The averaged wind field at the $850 \mathrm{hPa}$ level across all forecasts shows lower RMSE with the SKEB2 scheme than the control run without it. Biases at higher resolution also improve with the SKEB2 scheme, although at a lower magnitude because numerical diffusivity decreases when resolution increases (not shown).

\subsection{Location/intensity errors of extratropical cyclones}

In order to determine the impact of SKEB2's forecast degradation (Figures (1) and (2), Table 1) in midlatitude variability, we use the storm-matching technique for extratropical cyclones described in the methodology. The storms are tracked and paired to those in the analysis in order to obtain intensity and positional errors. The number of storms matched for the study is shown in Table 2; only storms developed before day 3 are taken into account, so after day 3 the number of storms drops as they decay and are not replaced. There are small differences amongst the number of storms matched for each experiment.

The results from averaged storms' distance and intensity errors versus forecast lead-time show that mean distance and intensity error decreases when resolution increases (Figure 4). This again 
(a) N96 GA3.0 - Analysis $850 \mathrm{hPa} \mathrm{T}+120$

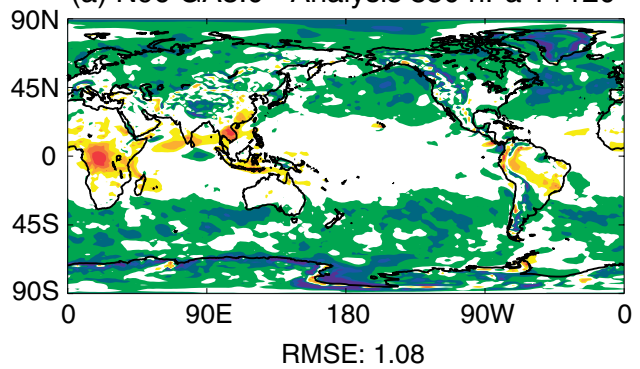

(b) SKEB2 - Analysis $850 \mathrm{hPa} \mathrm{T}+120$

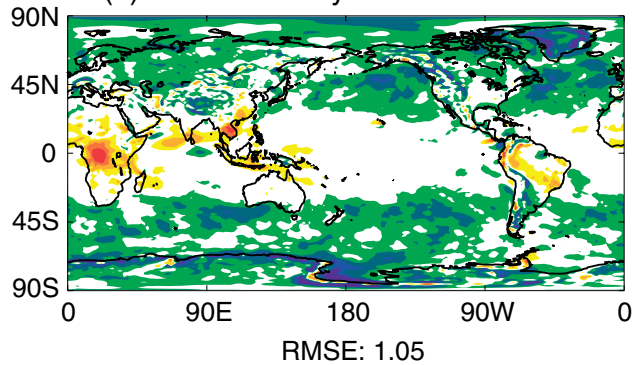

(c) SKEB2 br=0.1 - Analysis $850 \mathrm{hPa} \mathrm{T}+120$

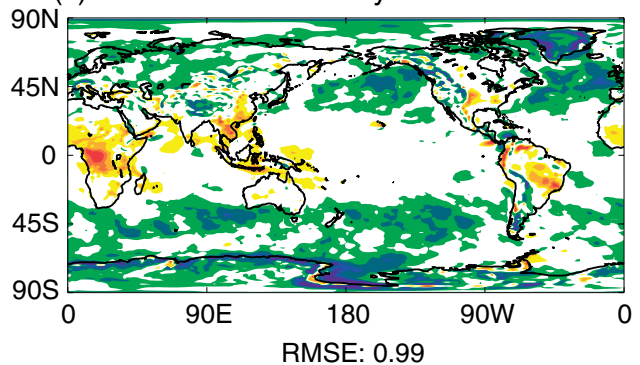

(d) SKEB2 br=0.2 - Analysis $850 \mathrm{hPa} \mathrm{T}+120$

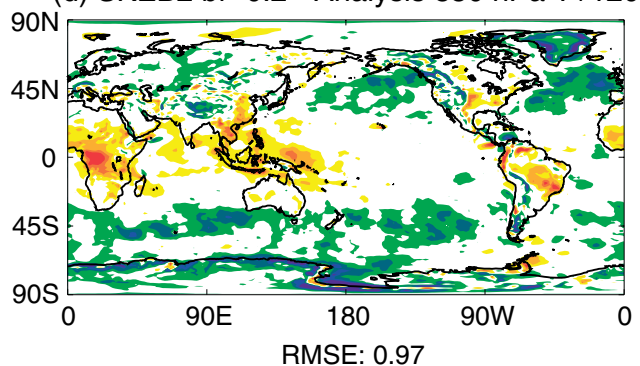

(e) SKEB2 br=0.3 - Analysis $850 \mathrm{hPa} \mathrm{T}+120$

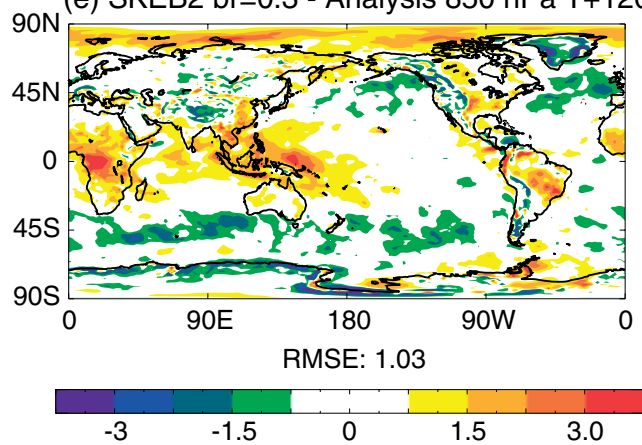

Figure 3. The MetUM bias (model - ECMWF analysis) of the modulus of wind at $850 \mathrm{hPa}\left(\mathrm{m} \mathrm{s}^{-1}\right.$ ) for (a) N96 control, (b) N96 SKEB2 default b $b_{R}$, (c) N96 SKEB2 $b_{R}=0.1$, (d) N96 SKEB2 $b_{R}=0.2$, (e) N96 SKEB2 $b_{R}=0.3$. The subtitle shows RMSE of the model average versus analysis average. This figure is available in colour online at wileyonlinelibrary.com/journal/qj

relates to the lack of variability, driven mainly by numerical dissipation that smooths the sharp gradients of winds that such storms produce. The SKEB2 scheme is beneficial in increasing the intensity of storms and it also introduces a positional error in all resolutions, but this is proportionally small to the intensity improvement. Errors in the $\mathrm{SH}$ are slightly larger in terms of position and intensity, but the intensity increase by the SKEB2
Table 2. Number of storms matched for each hemisphere and forecast day Numbers shown are the average amongst the different 5 day NWP experiments.

\begin{tabular}{lcc}
\hline & Northern Hemisphere & Southern Hemisphere \\
\hline $\mathrm{T}+24$ & 2160 & 2210 \\
$\mathrm{~T}+48$ & 2574 & 2603 \\
$\mathrm{~T}+72$ & 2379 & 2366 \\
$\mathrm{~T}+96$ & 1774 & 1698 \\
$\mathrm{~T}+120$ & 1135 & 1087 \\
\hline
\end{tabular}

scheme is equivalent for both hemispheres and resolutions. There is a clear problem with the way that the SKEB2 scheme modulates its perturbation across resolutions. The SKEB2 dissipation rate should be much higher and thus create a higher impact on the intensity at N96 than at N320 because dissipation is higher at lower resolutions, but our results show that the intensity increase is similar at both resolutions.

The same plot for different backscatter ratios at N96 is shown in Figure 5. The same pattern is amplified: location error increases but intensity biases are weaker. For $b_{\mathrm{R}}=0.3$ in the $\mathrm{NH}$ the storms become too active, with an intensity higher than in the analysis (Figure 5(c)). As suggested by the wind biases (Figure 3(e)) at this amplitude the SKEB2 forcing is probably larger than the energy dissipated, which creates overly intense storms. The default amplitude factor $b_{\mathrm{R}}=0.0275$ is ideal to simulate storms at the adequate magnitude in the $\mathrm{NH}$ (Figure 4(c)) at N320, nevertheless lower resolutions show that this factor is too low: Figure 5(c) indicates that the factor could be increased and the intensity in the $\mathrm{SH}$ would still be low (also shown in Figure 3(e)).

There is an obvious bias in our technique towards the simulation of weak storms (intensity lower than $3 \times 10^{-5} \mathrm{~s}^{-1}$ ) stronger than the analysis, because if the model weakens these storms they would not be strong enough to exist and be tracked by the RUTRACK algorithm. Figure 6 shows the reliability of the intensity of simulated storms, given an array of storms from the analysis within an intensity range; the average of the intensity of simulated storms of such an array would indicate whether the model tends to simulate any particular intensity range too weakly or too strongly. Intense storms are weakly simulated by the model, but they improve with resolution. On the other hand, the SKEB2 scheme with a strong forcing increases the intensity across the whole spectrum of storms intensities rather than at high intensities, where storms are too diffused. Again this is a side-effect of the numerical dissipation rate being unable to adequately scale up the dissipation of sharp vorticity gradients.

The SKEB2 scheme produces worse forecasts, which are driven by misplaced storms becoming stronger in the midlatitudes. The scheme invigorates the vorticity gradients diffused by the advection scheme, having a positive effect in the mean bias of the extratropics where winds are too slow. At low resolution the current amplitude of the scheme is not sufficient: the numerical dissipation rate computed by the SKEB2 scheme should be higher at low resolutions, but it appears to be constant across resolutions and storm intensities. In order to properly localize regions where intensity or location biases are prominent (i.e. around mountain ranges, land-sea contrast, strong convective regions) we would need more forecasts: the number we have is not sufficient to produce any significant regional results.

\section{Results for 20 year climate runs}

The differences in the mean climate amongst different members of the SKEB2 ensemble at the default $b_{\mathrm{R}}$ and $b_{\mathrm{R}}=0.1$ are not statistically significant at the $95 \%$ when compared with differences amongst members of the HadGEM2 ensemble. Probabilities given by $F$-test between the standard deviations of the SKEB2 and HadGEM2 ensembles for various variables and regions are low and beneath acceptable statistical significance levels. 
(a) Distance errors $\mathrm{NH}$

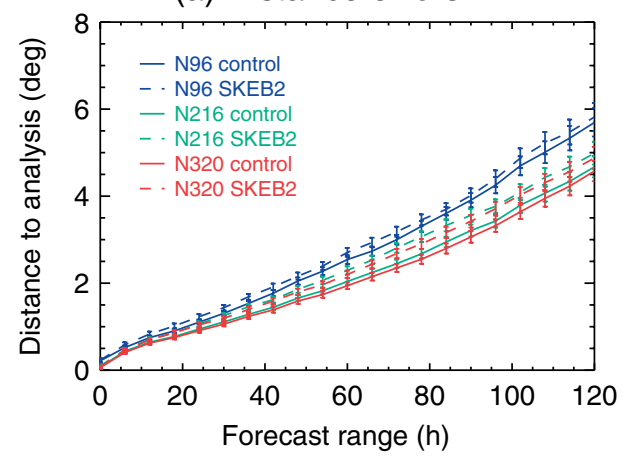

(c) Intensity difference $\mathrm{NH}$

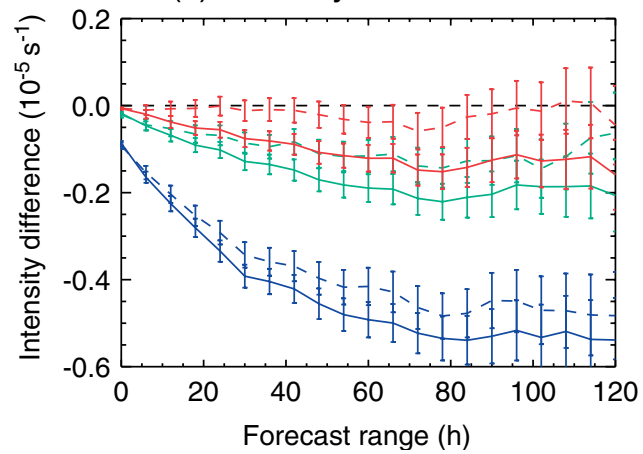

(b) Distance errors $\mathrm{SH}$

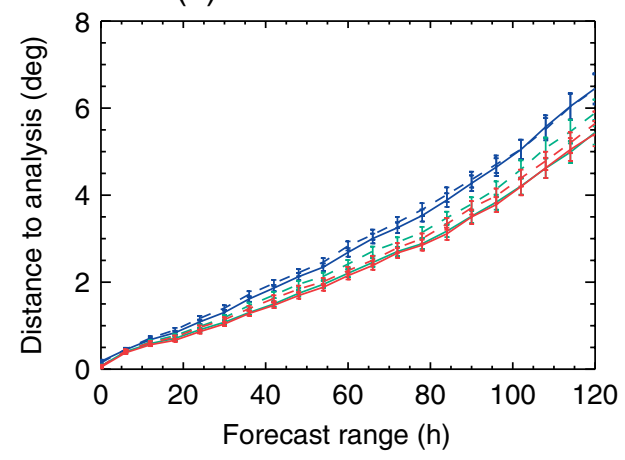

(d) Intensity difference $\mathrm{SH}$

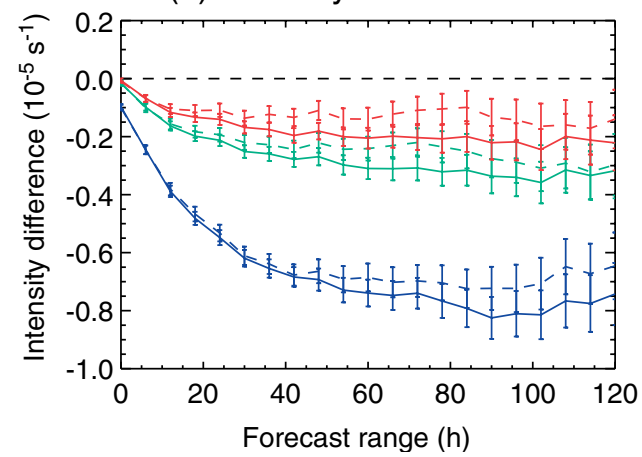

Figure 4. Distance (a,b) and intensity (c,d) differences of simulated storms matched to those analyzed. Continuous lines denote control and the dashed ones the runs with the SKEB2 scheme: blue is for N96, green N216 and red for N320. $(\mathrm{a}, \mathrm{c})$ The Northern Hemisphere and $(\mathrm{b}, \mathrm{d})$ the Southern hemisphere. This figure is available in colour online at wileyonlinelibrary.com/journal/qj

(a) Distance errors $\mathrm{NH}$

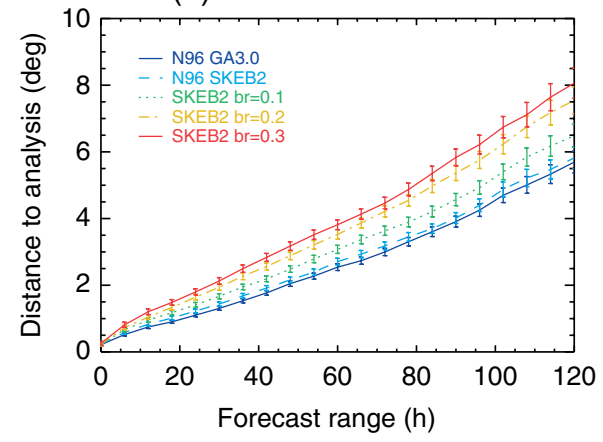

(c) Intensity difference $\mathrm{NH}$

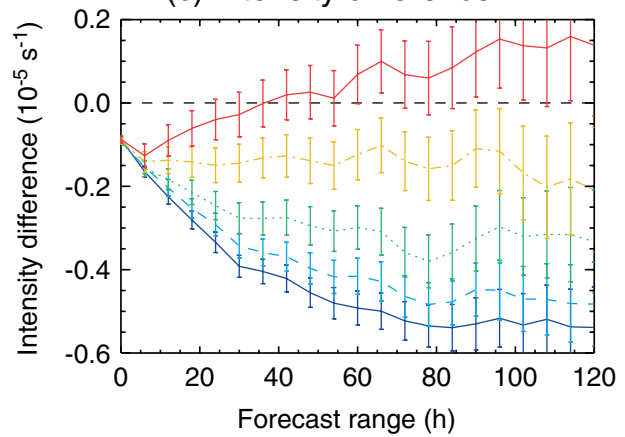

(b) Distance errors $\mathrm{SH}$

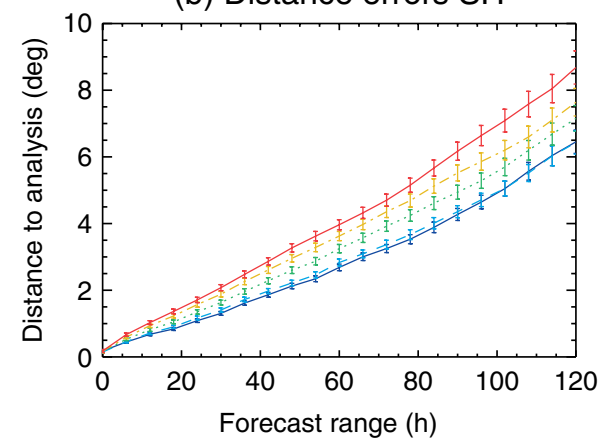

(d) Intensity difference SH

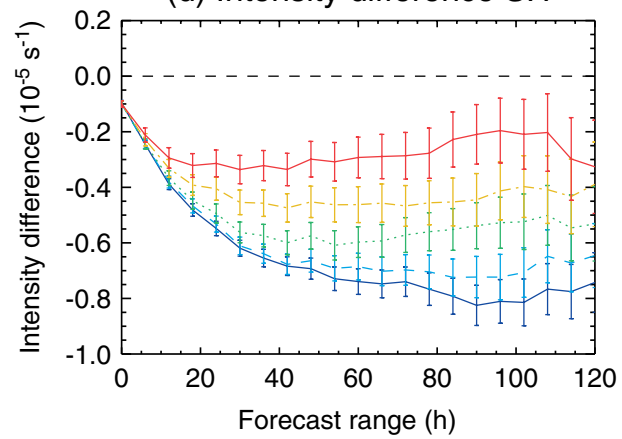

Figure 5. Same as Figure 4 but for different amplitudes of the SKEB2 scheme at N96. Dark blue is for control, pale dashed line for SKEB2 default $\left(b_{\mathrm{R}}=0.0275\right)$, green dotted line for $b_{\mathrm{R}}=0.1$, yellow dash-dotted for $b_{\mathrm{R}}=0.2$ and red dash-dotted for $b_{\mathrm{R}}=0.3$. This figure is available in colour online at wileyonlinelibrary.com/journal/qj

Monthly mean variability of wind at $850 \mathrm{hPa}$ is evaluated in Figure 7 , in which a comparison is presented of the mean value, standard deviation and confidence interval of all our simulations for four different regions with high variability: North Atlantic (Figure 7(a)) and North Pacific (Figure 7(b)) during boreal winter; Southern Ocean (Figure 7(c)) and West Indian Ocean (Figure 7(d)) during boreal summer. The MetUM, as with most climate models, has a severe deficiency simulating the mean climate over the Southern Ocean (Figure 7(c)) and the West
Indian Ocean (Figure 7(d)) - in both cases the control standard deviation does not reach the confidence interval of the observed analysis. The SKEB2 scheme shifts the mean climate in a uniform way according to its amplitude, and Figure 7 (d) shows how the scheme gradually increases the mean winds in the West Indian Ocean box across its amplitude.

The performance of the SKEB2 scheme on climate time-scales is neutral to positive. As Figure 7 shows: for the NH midlatitude the mean state of winds in these regions with high variability 


\section{Intensity Reliability diagram $\mathrm{T}+96 \mathrm{SH}$}

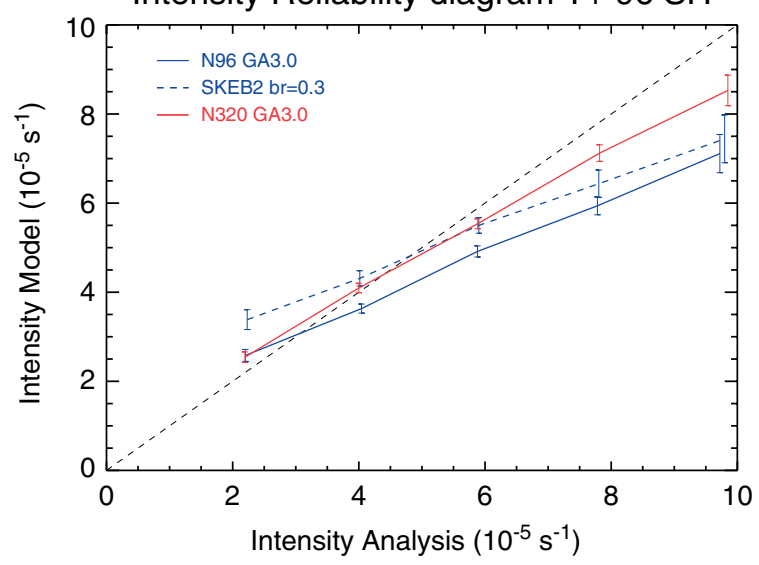

Figure 6. Reliability diagram for the intensity of storms. The mean intensity of simulated storms versus the mean intensity of analyzed storms within a given intensity segment of $2 \times 10^{-5} \mathrm{~s}^{-1}$. Confidence intervals are the standard deviation of the population divided by the square root of the length of the sample. Blue line is N96 control, dashed blue line N96 with the SKEB2 backscatter ratio of 0.3 and red line is N320 control. This figure is available in colour online at wileyonlinelibrary.com/journal/qj

is not severely affected by the scheme (Figure $7(\mathrm{a})$ and (b)); the Southern Ocean mean wind shows an insignificant increase (Figure 7(c)); for the West Indian monsoon the scheme has a positive effect and drifts the model towards the observed value, although winds become too strong for large $b_{\mathrm{R}}$ (Figure $7(\mathrm{~d})$ ).

As previously shown, at short-range (Figure 3 ) the SKEB2 sheme improves the biases and thus the spatial RMSE of the 20 year averaged fields against the ERAI reanalysis, which are similar to or lower than the control for winds at $850 \mathrm{hPa}$ (Figure 8) for different regions. By considering the global field of this variable we can gain a better understanding of where the model biases and the SKEB2 improvements are. There are two key areas where model biases are large and SKEB2 improvements are significant: the West Indian monsoon and the poleward side of the Southern Ocean (SO) lowlevel jet stream around Antarctica (Figure 9). These two biases are common amongst state-of-the-art climate models and relate to complex phenomena that span across different time-scales, such as the MJO and atmosphere-ocean exchange of mass, heat and momentum. In the following we analyse these two improvements separately.

\subsection{Southern ocean wind bias}

The $\mathrm{SH}$ jet stream at $850 \mathrm{hPa}$, also defined as the $\mathrm{SO}$ storm track because it is the region with the highest density of storms, is displaced equatorwards in the control, as shown in Figure 9(a), where strong winds in the $\mathrm{SH}$ are too strong on the equatorward side and too low on the poleward side. All the SKEB2 ensemble members partially correct the position of storm tracks, decelerating winds in the West Pacific, south of New Zealand, and accelerating winds around Cape Horn (Figure 9(c),(e),(g) and (i)).

We have run RUTRACK for the 20 year output of sixhourly winds at $850 \mathrm{hPa}$ for all the climate simulations, and computed statistics for the intensity and density of storms for two different reanalysis ERAI and MERRA. The negative impact of the SKEB2 scheme in the location of storms at short-range (Figures 4(a) and (b) and 5(a) and (b)) does not generate a degradation of the zonally averaged profile of storm density for three different basins - North Atlantic, Pacific and Southern Ocean (Figure 10(a)-(c)). Except for the high backscatter ratio simulation, the SKEB2's storm density for different backscatter ratios are between both reanalysis in all cases except high latitudes over Southern Ocean (in agreement with Figure 7(c)). As previously shown in Figures 4(c) and (d) and 5(c) and (d) the model simulates weaker storms than reality, which is also present at climate scales, where there is a gap between zonally averaged intensity of storms from model simulations and reanalysis (Figure $10(\mathrm{~d})-(\mathrm{f})$ ): this intensity gap is reduced when $b_{\mathrm{R}}$ increases as storms become more intense.

\subsection{Tropical biases}

The MetUM produces too much upper-level divergence in key areas such as the Pacific and Atlantic basins, Central America and the equatorial Indian Ocean. Divergence is associated with deep convection. Outgoing long-wave radiation (OLR) at the top of the atmosphere (TOA) is a good proxy for convection. As convection triggers and gives birth to cumulonimbus cells, the long-wave radiation from the Earth is trapped and not transmitted to space, and therefore regions with low OLR measured from satellites are convectively active at low latitudes. Excessive divergence is associated with too much convection, and thus thicker clouds with lower OLR (Figure 11(a)). All the SKEB2 simulations reduce the divergence over these high-convection areas, and this reduction seems to be proportional to the $b_{\mathrm{R}}$ backscatter ratio (Figure 11). The SKEB2 scheme also increases the weakly simulated winds over the Arabian Sea (Figure 9), improving the lack of divergence and thus excessive OLR over Indian and Maritime continents. As shown in Figure 3(e), winds are already too high at the highest backscatter ratio over the Maritime continent and West Pacific, generating a deficit of OLR and excessive precipitation over these area (not shown). The default value for the backscatter ratio produces barely significant differences to control (Figure 11(b)).

\subsection{Tropical intraseasonal variability}

The background-removed power spectrum of MetUM shows that the representation of some of the CCEWs is poor or missing (Figures 12(a) and 13(a)). The power of eastward-propagating Kelvin waves, key components for the MJO propagation, is too weak against observations for long periods and too strong for periods shorter than 3 days. When we increase SKEB2's $b_{\mathrm{R}}$ the power spectra of Kelvin waves slightly decreases, as shown in the symmetric spectra for zonal winds at $850 \mathrm{hPa}$ (Figure 12). The antisymmetric part of the spectra shows that the SKEB2 scheme leads to the emergence of a Rossby wave node with frequency lower than 3 days and wave number 5 propagating westward (Figure 13), but this node is not observed in the observations and control (Figure 13(f) and (a)), and other variables such as OLR show this unrealistic increase of the power of Rossby waves (not shown).

We have conducted an experiment at N96 with the highest backscatter ratio but with no forcing to the velocity potential in order to understand whether the emergence of the spurious Rossby wave is caused by the velocity potential forcing diminishing divergence at upper tropospheric levels. Results show no statistical significance between the simulation with the velocity potential forcing and that without. Biases in OLR are similar and the antisymmetrical background-removed power spectrum of horizontal winds at $850 \mathrm{hPa}$ also shows the spurious Rossby wave (not shown).

Other MJO metrics, such as the ratio between unfiltered winds at $850 \mathrm{hPa}$ and filtered between 20 and 100 days, or diagnostics to evaluate the MJO propagation through its different phases show little difference amongst the different SKEB2 simulations and the control.

Despite the emergence of this erroneous kind of variability in the horizontal wind spectrum, we find improvements in the temporal distribution of rain driven by the SKEB2 scheme. The power spectra of daily rain for the tropical summer (June-September; JJAS) averaged over 20 years and latitude bands between $5^{\circ} \mathrm{S}$ and $5^{\circ} \mathrm{N}$ show that the MetUM produces too much red noise at low frequencies and too little variability at high frequencies in comparison to the GPCP (Figure 14): the peak in 
(a) N. Atl. 65W-15W 35N-60N DJF

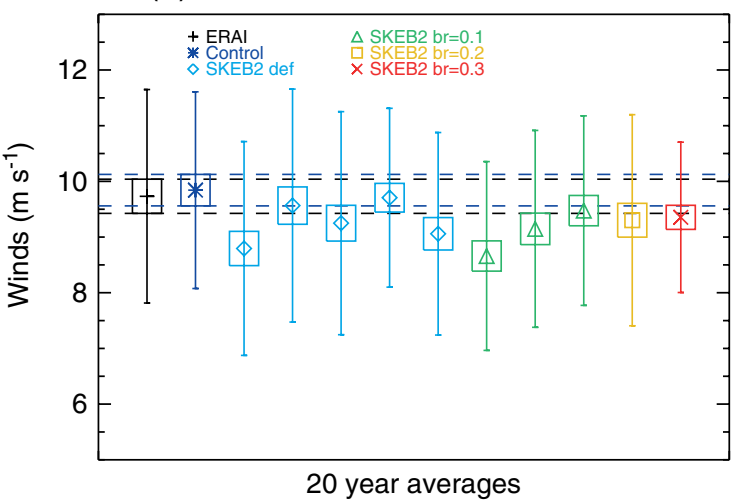

(c) S. O. 50S-70S JJA

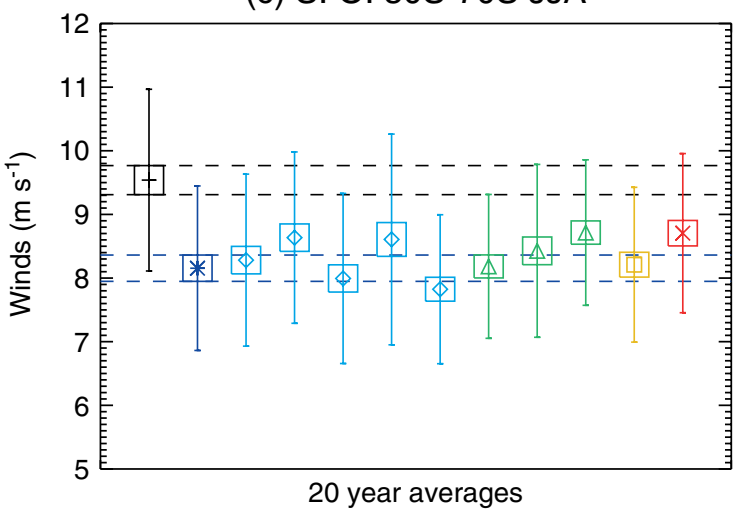

(b) N. Pac.150W-150E 30N-45N DJF

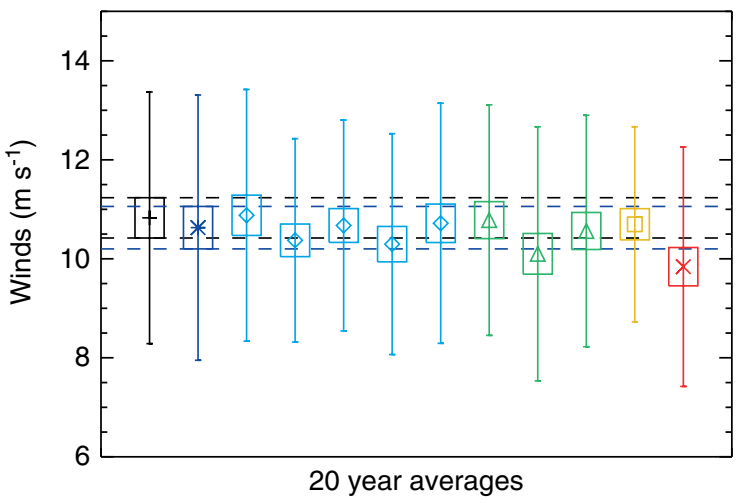

(d) West Indian O. 55E-75E 0-20N JJA

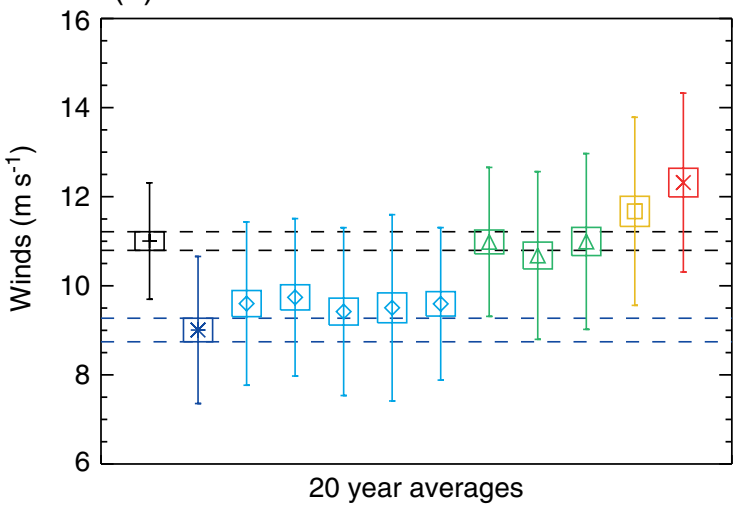

Figure 7. Average values (symbols), standard deviation (bars) and confidence intervals (boxes) of monthly mean winds at $850 \mathrm{hPa}$ for all the different climate runs plus ERAI reanalysis fo the period from January 1989 to December 2001: (a) North Atlantic section $\left(65^{\circ} \mathrm{W}-15^{\circ} \mathrm{W}, 35^{\circ} \mathrm{N}-60^{\circ} \mathrm{N}\right)$ for December, January and February (DJF); (b) North Pacific $\left(150^{\circ} \mathrm{W}-150^{\circ} \mathrm{E}, 30^{\circ} \mathrm{N}-45\right)$ for DJF; (c) Southern Ocean (whole longitudinal domain, $\left.50^{\circ} \mathrm{S}-70^{\circ} \mathrm{S}\right)$ for June, July and August (JJA); (d) West Indian Ocean $\left(55^{\circ} \mathrm{E}-75^{\circ} \mathrm{E}, 0-20^{\circ} \mathrm{N}\right)$ for JJA. Black with pluses is for ERAI; dark-blue with asterisk for control; pale blue with diamonds for the ensemble of the SKEB2 default amplitude; green with triangles for the ensemble of the SKEB2 with $b_{\mathrm{R}}=0.1$; yellow with squares $b_{\mathrm{R}}=0.2$; and red with crosses for $b_{\mathrm{R}}=0.3$ scheme backscatter ratio. Dashed lines denote the confidence interval of control and ERAI. This figure is available in colour online at wileyonlinelibrary.com/journal/qj

RMSE normalized to control of winds at $850 \mathrm{hPa}\left(\mathrm{m} \mathrm{s}^{-1}\right)$

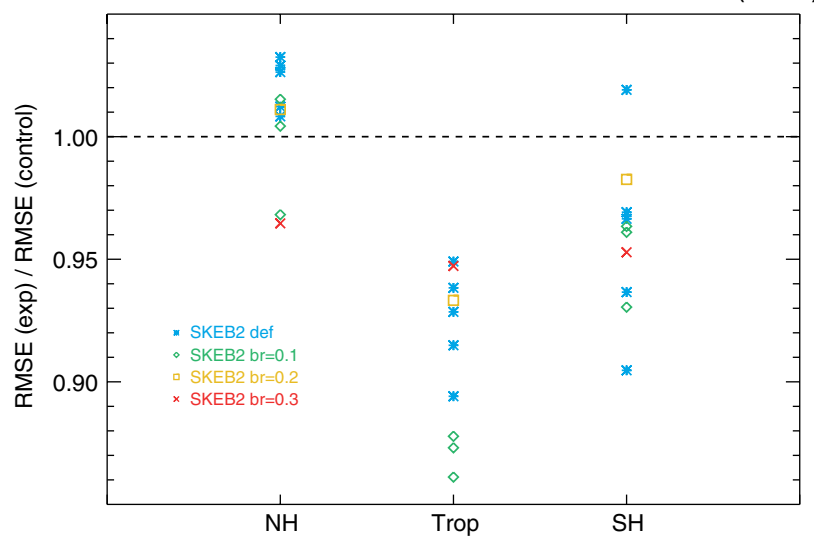

Figure 8. The RMSE ratio between the SKEB2 experiments and control for three different regions (as described in Figure 1). The SKEB2 default amplitude is represented by pale blue asterisks; SKEB2 with $b_{\mathrm{R}}=0.1$ by pale green diamonds; SKEB2 $b_{\mathrm{R}}=0.2$ by a yellow square; and SKEB $2 b_{\mathrm{R}}=0.3$ by red crosses. This figure is available in colour online at wileyonlinelibrary.com/journal/qj

the MJO between 30 and 60 days is absent, and the SKEB2 scheme produces a better representation of these frequency nodes over the Indian Ocean $\left(45-90^{\circ} \mathrm{E}\right)$.

Another deficient aspect of tropical convection is how intermittently the scheme is triggered, leading to an on-off convective rain pattern that is not realistic. In order to understand whether the SKEB2 scheme produces more long-lasting episodes of precipitation, we output from our simulations the convective rain for each time step during one season (JJAS for 1981, the beginning of the climate AMIP run): the power spectra of 1 day intervals over the box $60-70^{\circ} \mathrm{E}$ and $5^{\circ} \mathrm{S}-2.5^{\circ} \mathrm{N}$, a region where there is a large bias in OLR (Figure 11), is shown in Figure 15. For high frequencies (low number of time steps) the SKEB2 scheme produces less power than control, indicating that the convective precipitation is less intermittent.

\subsection{Impact of the SKEB2 scheme on other versions of the model}

These studies were repeated with a newer version of the model, which incorporates a new dynamical core. This new core (referred to here as ENDGame) corresponds to the non-mass conserving 'Standard SISL' version of the scheme described by Wood et al. (2013). The ENDGame is a semi-implicit semi-Lagrangian scheme that is solved using an iterative approach. The increased stability afforded by this approach has allowed a significant reduction in the amount of temporal off-centring used in the semi-implicit scheme. Additionally, no polar filtering is applied. Again the SKEB2 scheme seems to improve the intensity of storms as well as produce similar improvements in the magnitude and location of climate biases (not shown). This indicates that the results are not particularly specific to the control configuration being used.

\section{Discussion and conclusions}

The idea of using stochastic physics schemes to represent the atmospheric model uncertainty across time-scales is growing, given the theoretical arguments and the positive results that have been obtained for medium-range ensemble prediction systems. We have tested one of these schemes, a stochastic kinetic energy backscatter, commonly used in EPS for medium-range to seasonal prediction, under a variety of deterministic metrics to determine its advantages and limitations in the representation of atmospheric processes, using mid-latitude cyclone tracking 
(a) N96 GA3.0 minus ERAI

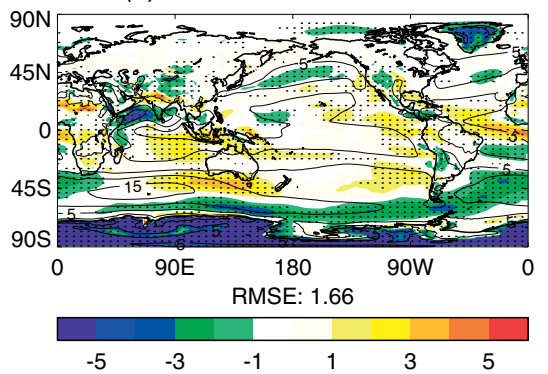

(d) SKEB2 br=0.1 minus ERAI

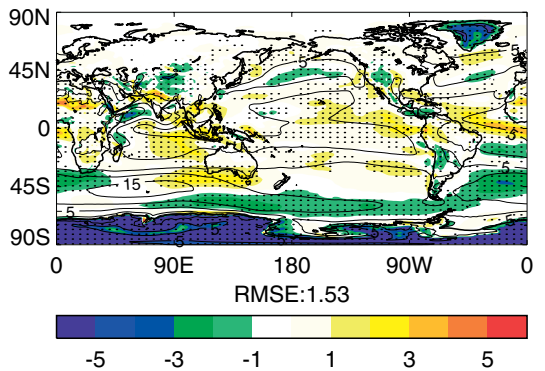

(g) SKEB2 br=0.2 minus N96 GA3.0

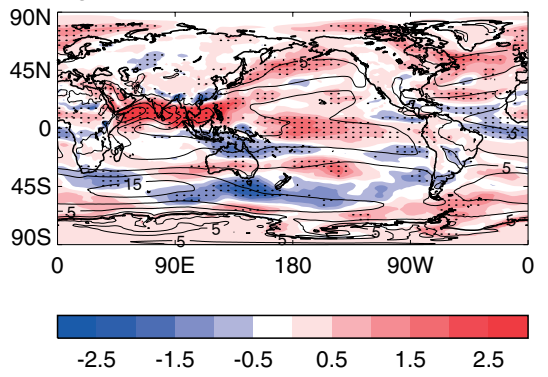

(b) SKEB2 minus ERAI

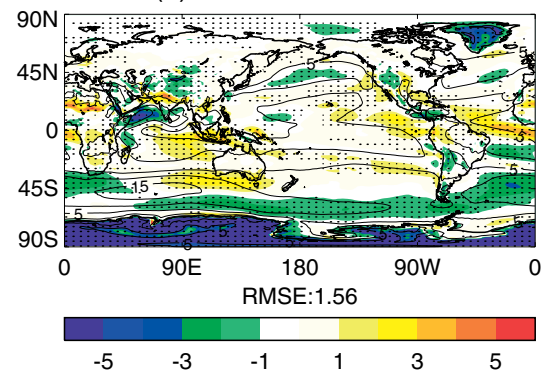

(e) SKEB2 br=0.1 minus N96 GA3.0

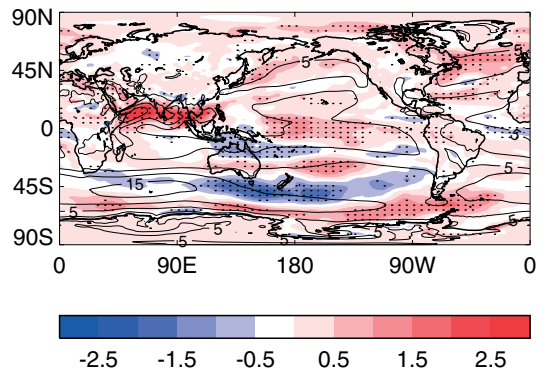

(h) SKEB2 $\mathrm{br}=0.3$ minus ERAI

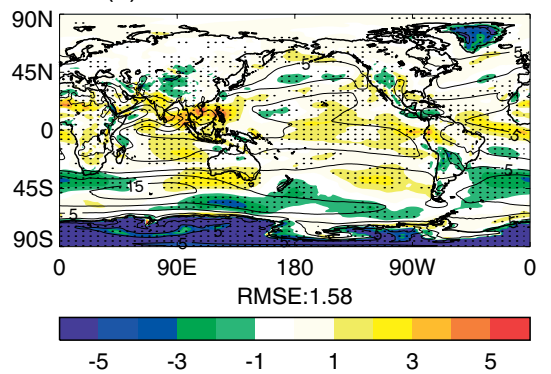

(c) SKEB2 minus N96 GA3.0

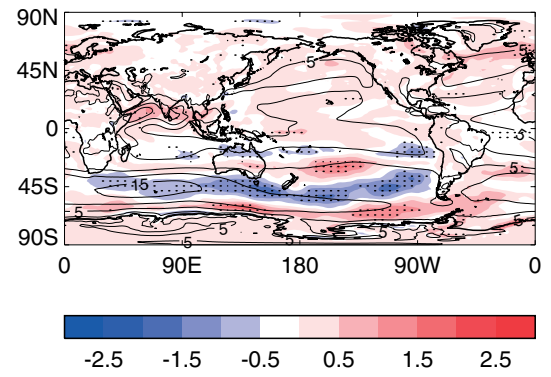

(f) SKEB2 br=0.2 minus ERAI

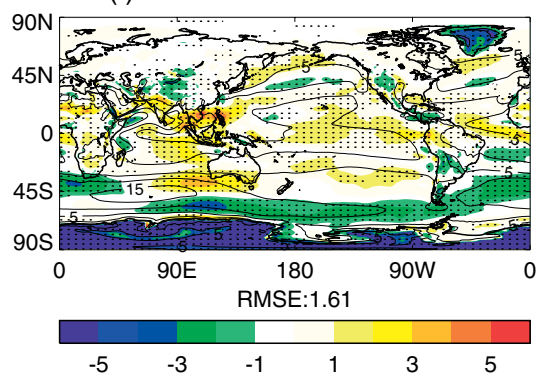

(i) SKEB2 br=0.3 minus N96 GA3.0

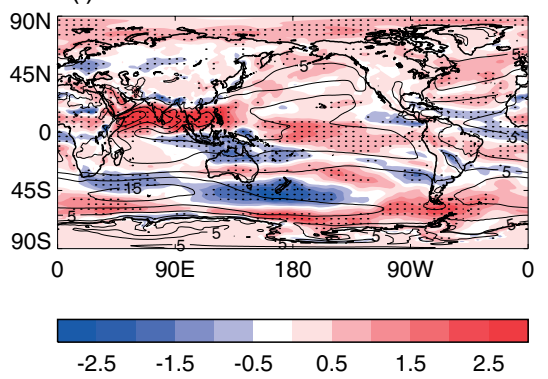

Figure 9. Modulus of winds at $850 \mathrm{hPa}$ differences $\left(\mathrm{m} \mathrm{s}^{-1}\right)$ in boreal summer (JJA). (a) Control biases to ERAI reanalysis during the interval January 1989 to December 2001; (b) the SKEB2 ensemble mean with default $b_{\mathrm{R}}=0.0275$ member minus ERAI; (c) the SKEB2 ensemble mean with default $b_{\mathrm{R}}=0.0275$ minus control; (d) the SKEB2 ensemble mean with $b_{\mathrm{R}}=0.1$ minus ERAI; (e) the SKEB2 ensemble mean with $b_{\mathrm{R}}=0.1$ minus control; (f) the SKEB2 with $b_{\mathrm{R}}=0.2$ minus ERAI; (g) the SKEB2 with $b_{\mathrm{R}}=0.2$ minus control; (h) the SKEB2 with $b_{\mathrm{R}}=0.3$ minus ERAI; (i) the SKEB2 with $b_{\mathrm{R}}=0.3$ minus control. Dotted areas denote significance above a 95\% level using a Student's $t$ test. Contours show ERAI reanalysis winds each $5 \mathrm{~m} \mathrm{~s}^{-1}$. Subtitles show the RMSE of the climate mean field versus ERAI. This figure is available in colour online at wileyonlinelibrary.com/journal/qj

(a) Zonal Storm Density for DJF in NAtl

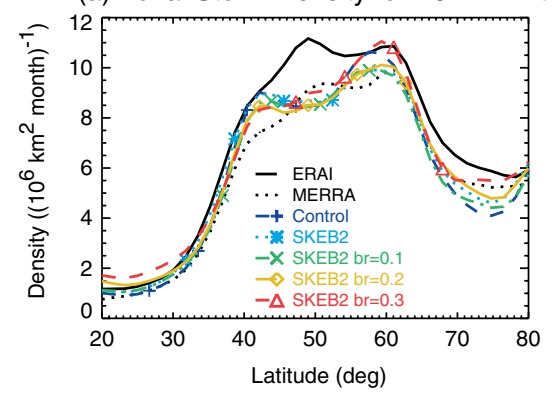

(d) Zonal Storm Intensity for DJF in NAtl

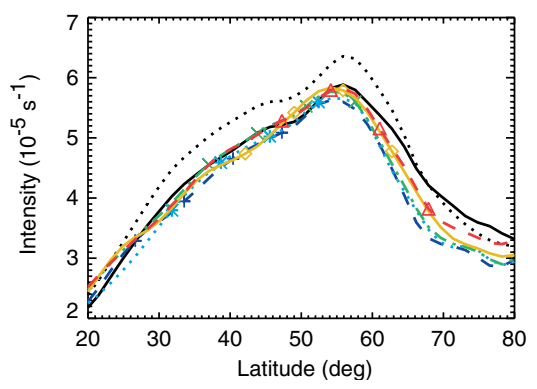

(b) Zonal Storm Density for DJF in NPac

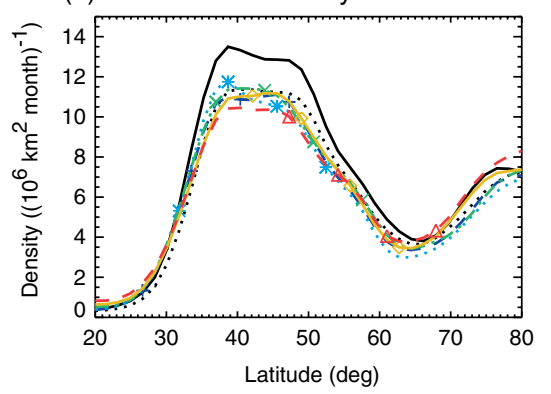

(e) Zonal Storm Intensity for DJF in NPac

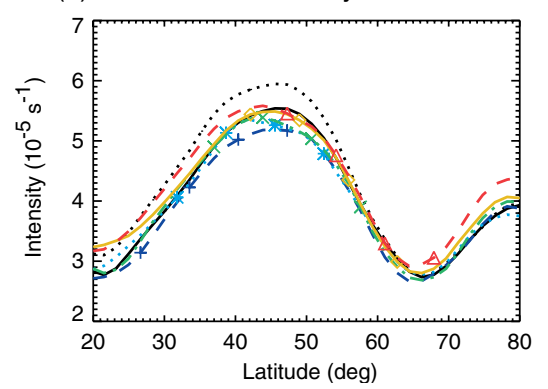

(c) Zonal Storm Density for JJA in SO

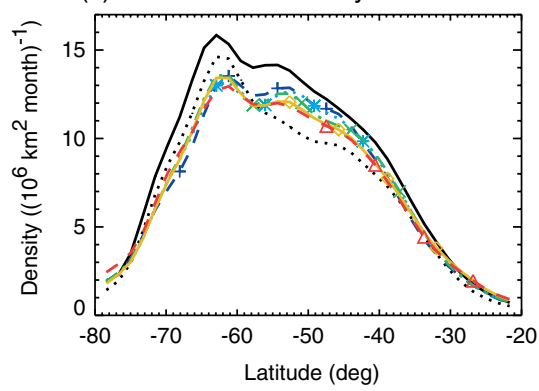

(f) Zonal Storm Intensity for JJA in SO

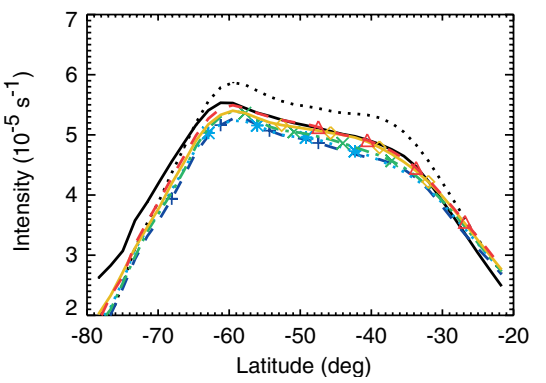

Figure 10. Zonally averaged profiles of: (a) storm density for the North Atlantic basin $\left(75^{\circ} \mathrm{W}-15^{\circ} \mathrm{E}\right)$ during DJF; (b) storm density for the North Pacific basin $\left(120^{\circ} \mathrm{W}-120^{\circ} \mathrm{E}\right)$ in DJF; (c) storm density for the Southern Ocean in JJA; (d) storm intensity for the North Atlantic in DJF; (e) storm intensity for the North Pacific in DJF; (f) storm intensity for the Southern Ocean in JJA. Black continuous line is for ERAI, black dotted line is for MERRA, dashed dark blue with pluses is for control, dashed pale blue with asterisk is the ensemble mean of the SKEB2 ensemble with default amplitude, green dotted with crosses is for $b_{\mathrm{R}}=0.1$; yellow dash-dotted with diamonds for $b_{\mathrm{R}}=0.2$. and red dash-dotted line with triangles is for $b_{\mathrm{R}}=0.3$. This figure is available in colour online at wileyonlinelibrary.com/journal/qj 
(a) OLW TOA (W/m²) N96 GA3.0 minus CERES

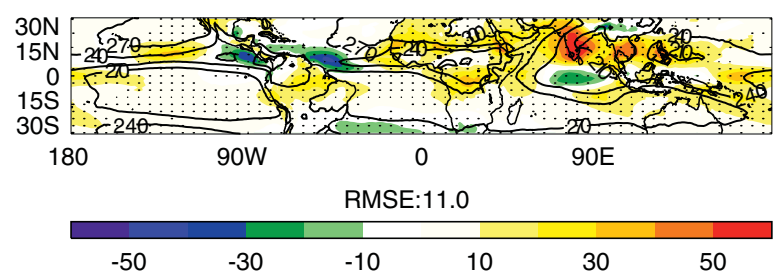

(b) SKEB2 minus N96 GA3.0

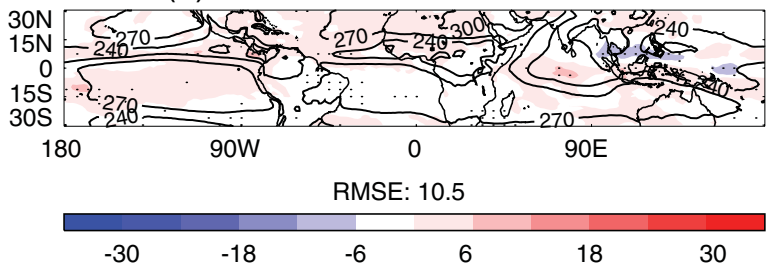

(c) SKEB2 br=0.1 minus N96 GA3.0

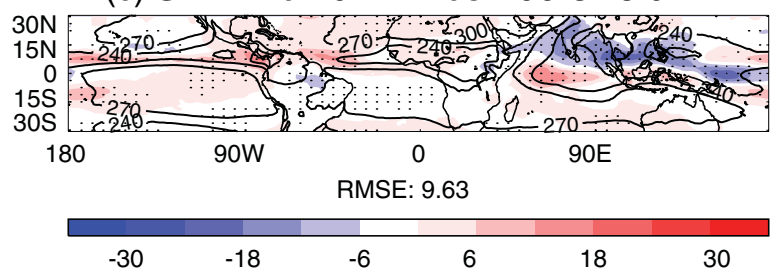

(d) SKEB2 br=0.2 minus N96 GA3.0

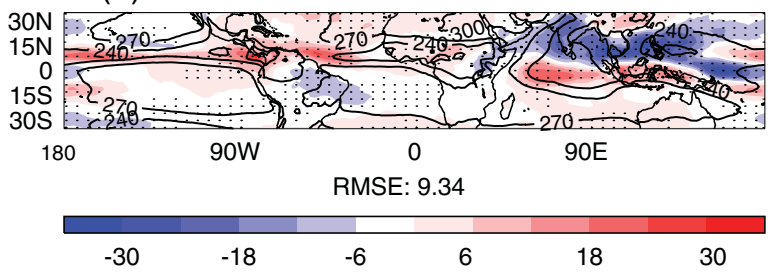

(e) SKEB2 br=0.3 minus N96 GA3.0

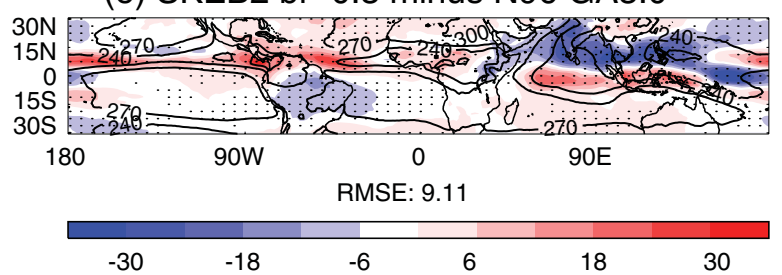

Figure 11. Outgoing longwave radiation (OLR) at the top of the atmosphere (TOA) for JJAS. (a) Control minus CERES. (b) The SKEB2 ensemble mean with default $b_{\mathrm{R}}=0.0275$ minus control. (c) The SKEB2 ensemble mean with default $b_{\mathrm{R}}=0.1$ minus control. (d) The SKEB2 with default $b_{\mathrm{R}}=0.2$ minus control. (e) The SKEB2 with default $b_{\mathrm{R}}=0.3$ minus control. Dotted areas denote statistical significance above the 95\% level using Student's $t$ test. Contours show CERES values each $30 \mathrm{~W} \mathrm{~m}^{-2}$. Subtitles show the RMSE of the climate mean to CERES. This figure is available in colour online at wileyonlinelibrary.com/journal/qj

techniques and specific diagnostics for the tropical climate simulation. We have included the SKEB2 scheme with the MetUM across different time-scales, at short-range 5 day deterministic forecasts across different horizontal resolutions and 20 year climate runs. In order to determine the sensitivity of the model to the stochastic physics scheme, we explore simulations at the low resolution with an increased backscatter ratio $b_{\mathrm{R}}$ from its default value of 0.0275 to $0.1,0.2$ and 0.3 respectively.

The SKEB2 scheme degrades individual deterministic shortrange forecasts for winds at $850 \mathrm{hPa}$, the level where synoptic cyclones are most active, but the mean bias of the forecasts is reduced: the MetUM winds at this level are weak in the extratropics most probably due to the numerical dissipation of the semi-Lagrangian scheme. The SKEB2 scheme was built to stochastically compensate this diffusivity of kinetic energy, so on average the energy backscatter of this scheme helps to invigorate the winds and to offset this problem: the higher the amplitude of the scheme the smaller the dissipation of winds over the extratropics. However, these experiments also show that the increase of winds in the Tropics is excessive, indicating that the forcing at those amplitudes might be higher than the energy lost by the process the SKEB2 scheme tries to represent. As tropical wind increments, mainly driven by the convective rate, are too high and winds in the extratropics, mainly driven by the numerical dissipation rate, are still not high enough, perhaps the ratio of between the numerical and convective dissipation is low and the scheme should amplify the numerical dissipation rate over the convective dissipation rate.

Unlike the high-resolution situation, the stochastic nature of the SKEB2 perturbation, although targeted to areas where there is numerical diffusivity and convective buoyancy, means that it is not always at the precise location or of the magnitude needed. If the extra energy added is slightly misplaced, or of inadequate magnitude, it might push the storm away from its natural path and change its intensity; thereby increasing the location and intensity error and subsequently increasing the RMSE and decreasing the anomaly correlation. The climatological density of storms, however, shows that the SKEB2 forcing is appropriate and, in certain latitudes, beneficial. The average intensity of extratropical storms is closer to analysis when we include the SKEB2 forcing; the extra kinetic energy input helps to strengthen gradients of vorticity that create stronger storms. However there seems to be a problem with the estimation of the numerical dissipation rate. Ideally, a stochastic energy backscatter scheme should produce larger perturbations when the resolution is lower, where there is more diffusivity of cyclones and larger energy cascades coming from subgrid processes. Also forcing should be larger in strong storms because these are more diffused by the advection scheme. At low resolution the SKEB2 increase in storm intensity is more or less similar to the rest of the resolutions used in this study and equally distributed along the spectra of intensities. This is an unsatisfactory aspect because we expect the numerical dissipation rate to asymptotically converge to zero as models move to higher and higher horizontal resolution and they produce less numerical diffusion at synoptic scales.

The SKEB2 scheme does not produce significant spread on climate scales in comparison with the HadGEM2 ensemble. The scheme cannot produce notable differences in the mean state of the climate that would help to estimate the model uncertainty.

On climate scales there are improvements that grow when the SKEB2 amplitude increases in two key areas where model performance is poor.

(1) Southern Ocean storm track is displaced equatorwards during June-August (JJA): members of the SKEB2 ensemble push it polewards, improving radiative fluxes over a region where there are large biases in surface temperature.

(2) Areas of deep convection: the MetUM at the GA3.0 configuration simulates strong divergence over some areas where deep convection occurs, such as the equatorial Indian Ocean, equatorial East Pacific and equatorial West Atlantic for the NH equatorial summer (May-October). The SKEB2 scheme reduces the mean divergence over these areas and improves the representation of clouds. The higher the backscatter ratio the higher the bias reduction: at the default value the SKEB2 impact is barely significant.

The analysis of the MJO using a process-based diagnostic package shows that these positive impacts on the mean climate are not driven by the right variability. The SKEB 2 scheme reduces the power of the Kelvin waves, which is already too low, and introduces a spurious Rossby wave of 3 day period: this wave is independent of the SKEB2 forcing to the velocity potential. The impact on the distribution of convective rain is positive over daily averaged and time-step by time-step temporal precipitation, thus convection seems more organized with the addition of the SKEB2 forcing at high frequencies. 

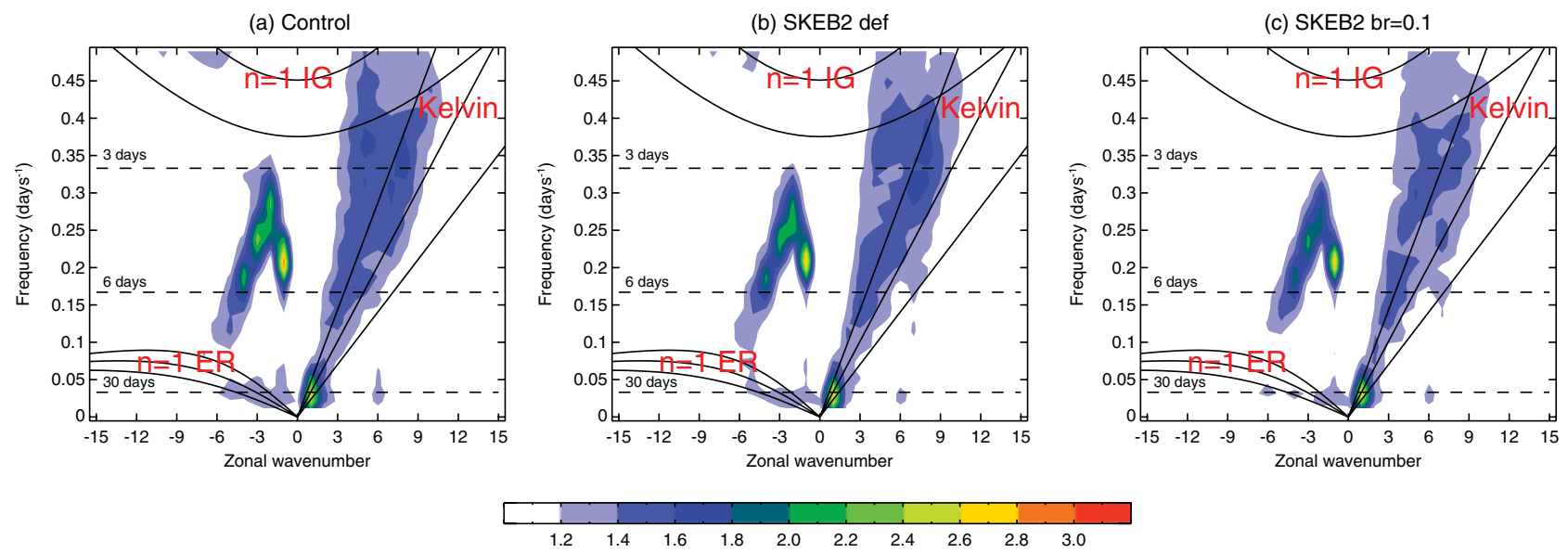

(d) SKEB2 $\mathrm{br}=0.2$

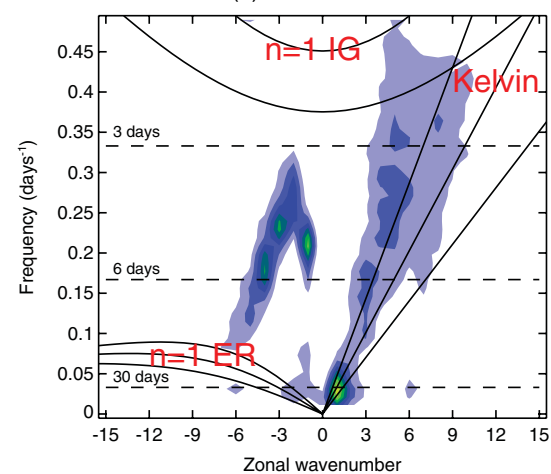

(e) SKEB2 br=0.3
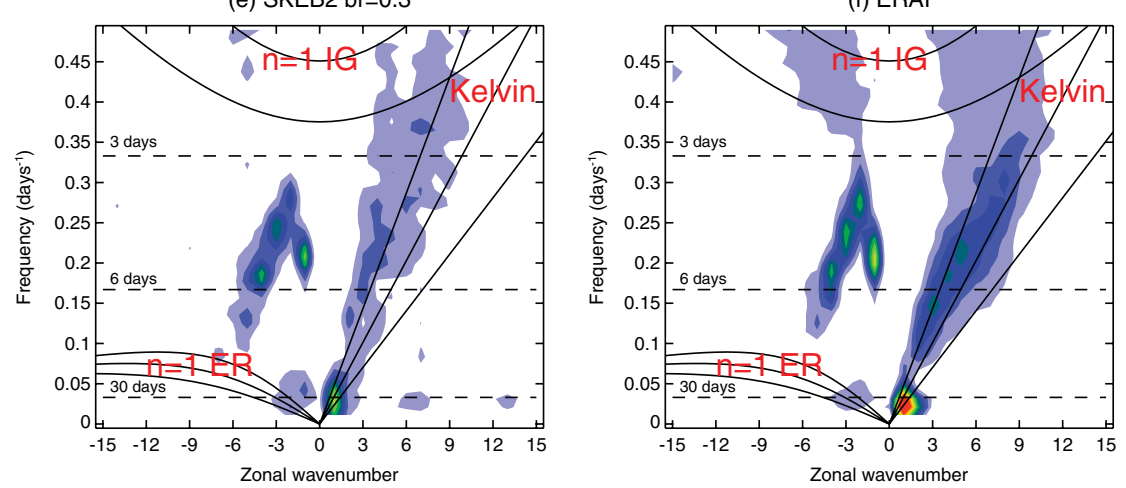

Figure 12. Background-removed symmetric power spectra for horizontal wind at $850 \mathrm{hPa}$. Horizontal dashed lines indicate wave periods for 30,6 and 3 days. Idealized solutions of the tropical waves are shown for equivalents depths of 12,25 and $50 \mathrm{~m}$, for $n=1$ equatorial Rossby waves (ER), $n=1$ inertio-gravity wave and Kelvin wave. (a) Control, (b) the SKEB2 default $b_{\mathrm{R}}=0.0275$, (c) the SKEB2 $b_{\mathrm{R}}=0.1$, (d) the SKEB2 $b_{\mathrm{R}}=0.2$, (e) the SKEB2 $b_{\mathrm{R}}=0.3$ and (f) ERA Interim. This figure is available in colour online at wileyonlinelibrary.com/journal/qj
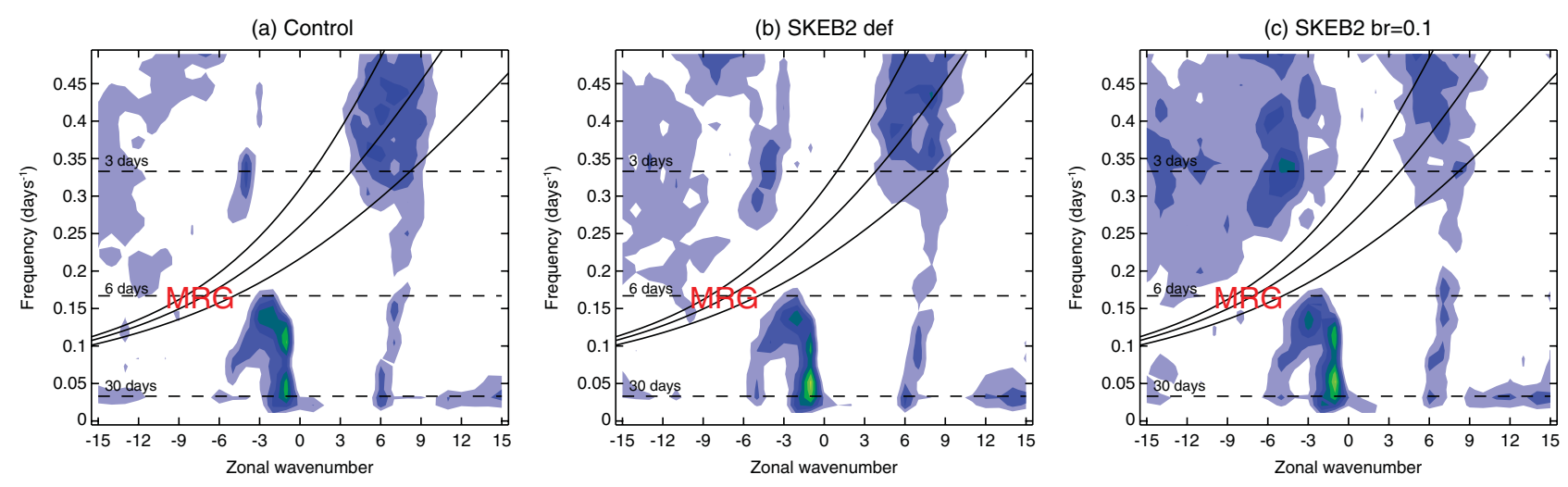

(d) SKEB2 br=0.2
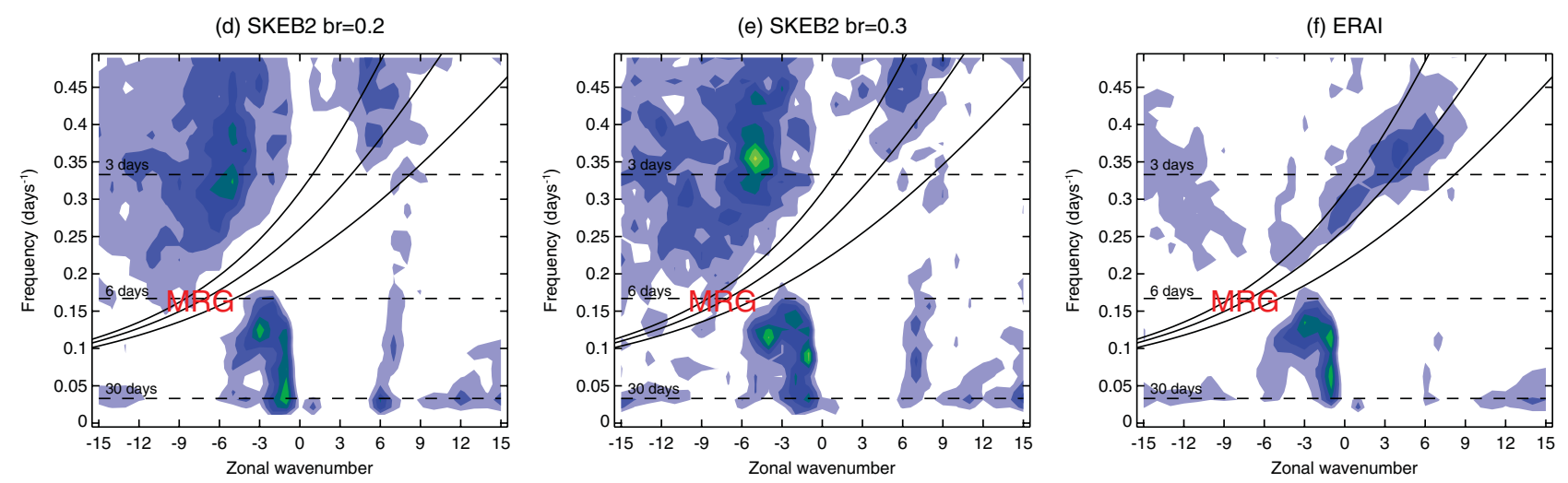

Figure 13. Background-removed anti-symmetric power spectra for horizontal wind at $850 \mathrm{hPa}$. The idealized solution for a mixed Rossby-Gravity wave for $n=0$ (MRG) is displayed with equivalent depths of 12, 25 and $50 \mathrm{~m}$. Same order as Figure 12. This figure is available in colour online at wileyonlinelibrary.com/journal/qj 

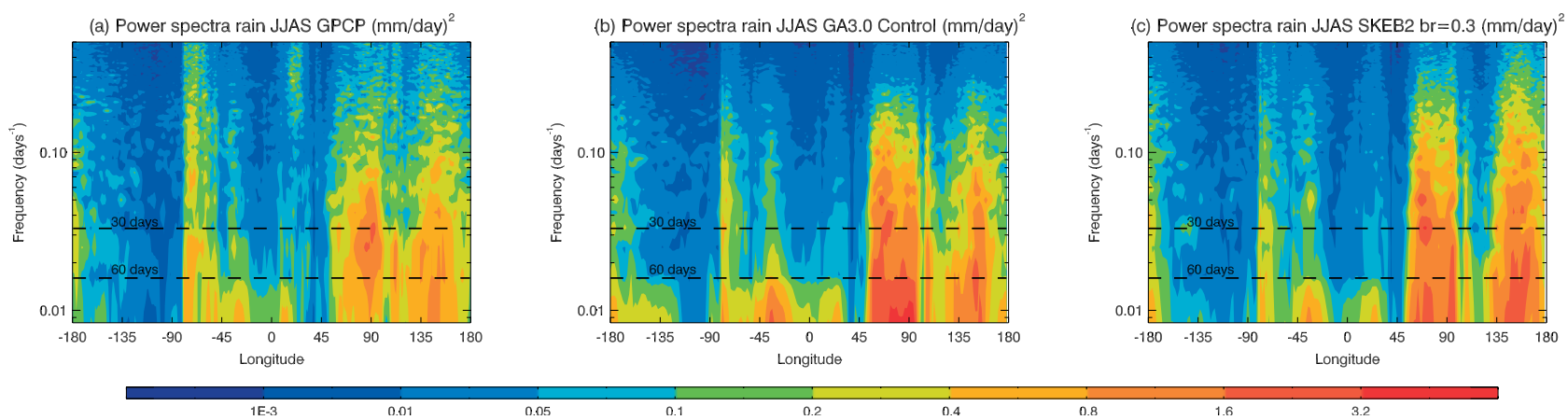

Figure 14. Latitudinally averaged $\left(5^{\circ} \mathrm{S}-5^{\circ} \mathrm{N}\right)$ power spectra for precipitation at different longitudes for (a) GPCP, (b) control and (c) the SKEB2 scheme with $b_{\mathrm{R}}=$ 0.3 ; for tropical summer (JJAS) 1 day averaged dataset. Dashed lines indicate frequencies equivalent to periods of 30 and 60 days. This figure is available in colour online at wileyonlinelibrary.com/journal/qj

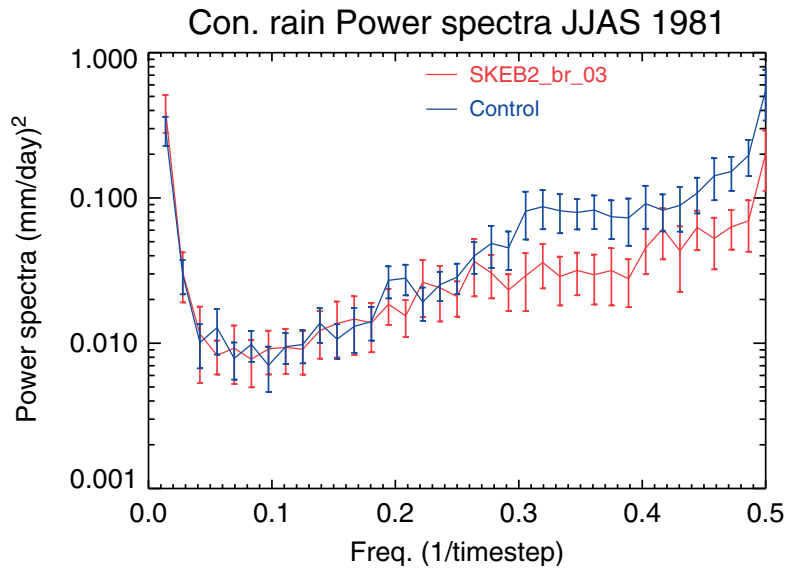

Figure 15. Convective rain power spectrum of 1 day intervals over an Indian Ocean box $\left(60-70^{\circ} \mathrm{E}\right.$ and $\left.5^{\circ} \mathrm{S}-2.5^{\circ} \mathrm{N}\right)$. The dataset is all the time steps of JJAS for 1981. Blue line is control and red is the SKEB2 scheme with the highest backscatter ratio. This figure is available in colour online at wileyonlinelibrary.com/journal/qj

Experiments were repeated with a new physics package plus the new MetUM's dynamical core ENDgame, which is less diffusive. Despite several of the biases being reduced, the SKEB2 impacts are comparable to those observed against GA3.0; therefore the scheme consistently produces the similar impacts on the variability of the model.

In its current representation, however, the SKEB2 scheme has some deficiencies and it might be further improved. The numerical dissipation rate does not seem to scale well across resolutions, the improvements in the intensity of storm are of equal magnitude across different intensities whereas it should be stronger for intense storms that are normally too diffused by the model. Other options to compute the numerical dissipation could be explored. For example, the use of biharmonic dissipation of the relative vorticity, which according to McCalpin et al. (1988) scales like the diffusion caused by the cubic interpolation to the departure point, and thus more in agreement with the implicit diffusion of the Semi-Lagrangian scheme. In the Tropics the convective rate seems to damp divergence at the wrong frequencies, provoking the emergence of spurious Rossby waves and damping the power of Kelvin waves.

The results described are different to those reported by Berner et al. (2012) using the spectral stochastic backscatter scheme (SPBS) in the IFS. The schemes' numerical and convective dissipation rates are computed differently and the SKEB2 scheme has a vertical distribution of the forcing pattern that is slightly tilted to account for baroclinic waves. The IFS suffers from a lack of upper-level divergence, which the SPBS helps to increase everywhere, leading to excessive divergence over the Tropics and an overreactive synoptic activity over the Southern Ocean. On the other hand, the SPBS increases the power spectra of eastward propagating gravity waves. Differences between the IFS and MetUM are broad and varied; therefore a similar scheme would make the model react differently to an equivalent forcing.

Often critics of stochastic physics assume that it is hard to distinguish when the scheme has been tuned up excessively. Here we have shown by making use of different metrics that it is relatively easy to monitor if the scheme forcing is too strong. When we use a high-amplitude factor for the SKEB2 scheme, biases in the Tropics become too large. By using the default amplitude $b_{\mathrm{R}}$ we can produce storm intensities that are quite similar to those observed in the NH at N320, but at N96 these are too low and the backscatter ratio needs to be tuned up to increase the benefits of the scheme.

The SKEB2 scheme helps to improve the representation of the uncertainty of physics on dynamical processes, such as the intensity of midlatitude cyclones or the organization of convection. These improvements lead to a better representation of the mean intensity of an ensemble of midlatitude storms or a reduction of tropical biases in climate simulations, which are associated with the coupling between convection and dynamics. However, it seems to add an element of negative spatial and temporal displacement, as storms deviate more and CCEWs travel with the wrong dispersion relationship. There is some suspicion that the large scales of the scheme's stochastic forcing could be interfering with these well-simulated synoptic phenomena. Future research should investigate the effects of stochastic forcing at low wave numbers and whether the scheme could be replaced or complemented by a deterministic backscatter scheme forcing large scales, such as the vorticity confinement (Sanchez et al., 2012), which adds momentum in areas where there are sharp vorticity gradients.

\section{Acknowledgements}

Thanks to Kevin Hodges and Lizzie Froude for their help regarding the use of the RUTRACK code and matching technique. Claudio Sanchez and Keith Williams were supported by the Joint DECC/Defra Met Office Hadley Centre Climate Programme (GA01101). Finally, the authors acknowledge the helpful and insightful comments of two anonymous referees.

\section{References}

Adler RF, Huffman GJ, Chang A, Ferraro R, Xie P-P, Janowiak J, Rudolf B, Schneider U, Curtis S, Bolvin D, Gruber A, Susskind J, Arkin P, Nelkin E. 2003. The Version-2 Global Precipitation Climatology Project (GPCP) monthly precipitation analysis (1979-present). J. Hydrometeorol. 4: $1147-1167$.

Arribas A, Glover M, Maidens A, Peterson K, Gordon M, MacLachlan C, Graham R, Fereday D, Camp J, Scaife AA, Xavier P, McLean P, Colman A, Cusack S. 2011. The GloSea4 ensemble prediction system for seasonal forecasting. Mon. Weather Rev. 139: 1891-1910.

Bengtsson L, Steinheimer M, Bechtold P, Geleyn J-F. 2013. A stochastic parametrization for deep convection using cellular automata. Q. J. R. Meteorol. Soc. 139: 1533-1543, doi: 10.1002/qj.2108.

Berner J, Doblas-Reyes FJ, Palmer TN, Shutts G, Weisheimer A. 2008. Impact of a quasi-stochastic cellular automaton backscatter scheme on the systematic 
error and seasonal prediction skill of a global climate model. Philos. Trans. R. Soc. A366: 2559-2577.

Berner J, Shutts G, Leutbecher M, Palmer T. 2009. A spectral stochastic kinetic energy backscatter scheme and its impact on flow-dependent predictability in the ECMWF ensemble prediction system. J. Atmos. Sci. 66: 603-626.

Berner J, Ha S-Y, Hacker JP, Fournier A, Snyder C. 2012a. Model uncertainty in a mesoscale ensemble prediction system: Stochastic versus multiphysics representations. Mon. Weather Rev. 139: 1972-1995.

Berner J, Jung T, Palmer TN. 2012b. Systematic model error: The impact of increased horizontal resolution versus improved stochastic and deterministic parameterizations. J. Clim. 25: 4946-4962, doi: http://dx.doi. org/10.1175/JCLI-D-11-00297.1.

Bosilovich MG, Chen J, Robertson FR, Adler RF. 2008. Evaluation of global precipitation in reanalyses. J. Appl. Meteorol. Climatol. 47: 2279-2299.

Bowler NE, Arribas A, Mylne KR, Robertson KB, Beare SE. 2008. The MOGREPS short-range ensemble prediction system. Q. J. R. Meteorol. Soc. 134: 703-722.

Brown A, Milton S, Cullen M, Golding B, Mitchell J, Shelly A. 2012. Unified modeling and prediction of weather and climate: A 25-year journey. Bull. Am. Meteorol. Soc. 93: 1865-1877, doi: http://dx.doi.org/10.1175/BAMSD-12-00018.1.

Buizza R, Miller M, Palmer TN. 1999. Stochastic representation of mode uncertainties in the ECMWF ensemble prediction system. Q. J. R. Meteorol. Soc. 125: 2887-2908, doi: 10.1256/smsqj.56005.

Collins WJ, Bellouin N, Doutriaux-Boucher M, Gedney N, Halloran P, Hinton T, Hughes J, Jones CD, Joshi M, Liddicoat S, Martin G, O'Connor F, Rae J, Senior C, Sitch S, Totterdell I, Wiltshire A, Woodward S. 2011 Development and evaluation of an Earth-system model - HadGEM2. Geosci. Model Dev. Discuss. 4: 997-1062, doi: 10.5194/gmdd-4-997-2011.

Cullen MJP. 1993. The unified forecast/climate model. Meteorol. Mag. 122: $81-94$.

Davies T, Cullen MJP, Malcolm AJ, Mawson MH, Staniforth A, White AA Wood N. 2005. A new dynamical core for the Met Office's global and regional modelling of the atmosphere. Q. J. R. Meteorol. Soc. 131: 1759-1782.

Dee DP, Uppala SM, Simmons AJ, Berrisford P, Poli P, Kobayashi S, Andrae U, Balmaseda MA, Balsamo G, Bauer P, Bechtold P, Beljaars ACM, van de Berg L, Bidlot J, Bormann N, Delsol C, Dragani R, Fuentes M, Geer AJ, Haimberger L, Healy SB, Hersbach H, Hólm EV, Isaksen L, Kållberg P, Köhler M, Matricardi M, McNally AP, Monge-Sanz BM, Morcrette J-J, Park B-K, Peubey C, de Rosnay P, Tavolato C, Thépaut J-N, Vitart F. 2011. The ERA-Interim reanalysis: Configuration and performance of the data assimilation system. Q. J. R. Meteorol. Soc. 137:553-597, doi: 10.1002/qj.828.

Doblas-Reyes FJ, Weisheimer A, Déqué M, Keenlyside N, McVean M, Murphy JM, Rogel P, Smith D, Palmer TN. 2009. Addressing model uncertainty in seasonal and annual dynamical seasonal forecasts. Q. J. R. Meteorol. Soc. 135: $1538-1559$.

Eckermann SD. 2011. Explicitly stochastic parameterization of nonorographic gravity wave drag. J. Atmos. Sci. 68: 1749-1765, doi: http://dx.doi.org/10. 1175/2011JAS3684.1.

Froude LSR. 2010. TIGGE: Comparison of the prediction of Northern Hemisphere extratropical cyclones by different ensemble prediction systems. Weath. Forecasting 25: 819-836.

Froude LSR. 2011. TIGGE: Comparison of the prediction of southern hemisphere extratropical cyclones by different ensemble prediction systems. Weather and Forecasting 26: 388-398.

Froude LSR, Bengtsson L, Hodges KI. 2007. The prediction of extratropical storm tracks by the ECMWF and NCEP Ensemble Prediction Systems. Mon. Weather Rev. 135: 2545-2567.

Gates WL, Boyle JS, Covey C, Dease CG, Doutriaux CM, Drach RS, Fiorino M, Gleckler PJ, Hnilo JJ, Marlais SM, Phillips TJ, Potter GL, Santer BD, Sperber KR, Taylor KE, Williams DN. 1999. An overview of the results of the Atmospheric Model Intercomparison Project (AMIP I). Bull. Am. Meteorol. Soc. 80: 29-55.

Hodges KI. 1994. A general method for tracking analysis and its application to meteorological data. Mon. Weather Rev. 122: 2573-2586.

Hodges KI. 1995. Feature tracking on the unit sphere. Mon. Weather Rev. 123 $3458-3465$.

Hodges KI. 1996. Spherical nonparametric estimators applied to the UGAMP model integration for AMIP. Mon. Weather Rev. 124: 2914-2932.

Hoskins BJ. 2012. The potential for skill across the range of the seamless weather-climate prediction problem: A stimulus for our science. Q. J. R. Meteorol. Soc. 139: 573-584, doi: 10.1002/qj.1991.

Hoskins BJ, Hodges KI. 2002. New perspectives on the Northern Hemisphere winter storm tracks. J. Atmos. Sci. 59: 1041-1061.

Jung T, Palmer TN, Shutts GJ. 2005. Influence of a stochastic parameterization on the frequency of occurrence of North Pacific weather regimes in the ECMWF model. Geophys. Res. Lett. 32: L23811, doi: 10.1029/2005GL024248.

Kiladis GN, Wheeler MC, Haertel PT, Straub KH, Roundy PE. 2009. Convectively coupled equatorial waves. Rev. Geophys. 47: RG2003.
Lang STK, Leutbecher M, Jones SC. 2012. Impact of perturbation methods in the ECMWF ensemble prediction system on tropical cyclone forecasts. $Q$. J. R. Meteorol. Soc. 138: 2030-2046, doi: 10.1002/qj.1942.

McCalpin JD. 1988. A quantitative analysis of the dissipation inherent in semiLagrangian advection. Mon. Weather Rev. 116: 2330-2336, doi: http:// dx.doi.org/10.1175/1520-0493(1988)116<2330:AQAOTD>2.0.CO;2.

Palmer TN. 2001. A nonlinear dynamical perspective on model error: A proposal for non-local stochastic-dynamic parameterization in weather and climate prediction. Q. J. R. Meteorol. Soc. 127: 279-304.

Palmer TN, Buizza R, Doblas-Reyes FJ, Jung T, Leutbecher M, Shutts GJ, Steinheimer M, Weisheimer A. 2009. Stochastic Parametrization and Model Uncertainty, Technical Memorandum 598 European Centre Medium Range Weather Forecasts: Reading, UK.

Plant RS, Craig CG. 2008. A stochastic parameterization for deep convection based on equilibrium statistics. J. Atmos. Sci. 65: 87-105.

Sanchez C, Williams KD, Shutts GJ, McDonald RE, Hinton TJ, Senior CA, Wood N. 2012. Towards the development of a robust model hierarchy: Investigation of dynamical limitations at low resolution and possible solutions. Q. J. R. Meteorol. Soc. 139: 75-84, doi: 10.1002/qj.1971.

Senior CA, Arribas A, Brown AR, Cullen MJP, Johns TC, Martin GM, Milton SF, Webstre S, Williams KD. 2011. Synergies between numerical weather prediction and general circulation climate models. In The Development of Atmospheric General Circulation Models, Donner L, Shubert W, Sommerville R (eds.). Cambridge University Press: New York, NY; p. 225.

Shutts GJ. 2005. A kinetic energy backscatter algorithm for use in ensemble prediction systems. Q. J. R. Meteorol. Soc. 131: 3079-3102.

Shutts GJ. 2013. Coarse graining the vorticity equation in the ECMWF Integrated Forecasting System: The search for kinetic energy backscatter. J. Atmos. Sci. 70: 1233-1241.

Shutts GJ, Palmer TN. 2007. Convective forcing fluctuations in a cloudresolving model: Relevance to the stochastic parameterization problem. J. Clim. 20: 187-202.

Slingo J, Palmer TN. 2011. Uncertainty in weather and climate prediction. Philos. Trans. R. Soc. London, Ser. A 369: 4751-4767, doi: 10.1098/rsta.2011. 0161.

Teixeira J, Reynolds C. 2008. Stochastic nature of physical parameterizations in ensemble prediction: A stochastic convection approach. Mon. Weather Rev. 136: 483-496, doi: 10.1175/2007MWR1870.1.

Tennant WJ, Shutts GJ, Arribas A, Thompson SA. 2011. Using a stochastic kinetic energy backscatter scheme to improve MOGREPS probabilistic forecast skill. Mon. Weather Rev. 139: 1190-1206.

Thuburn J, Kent J, Wood N. 2013. Cascades, backscatter and conservation in numerical models of two-dimensional turbulence. Q. J. R. Meteorol. Soc., doi: $10.1002 /$ qj.2166.

Waliser D, Sperber K, Hendon H, Kim D, Maloney E, Wheeler M, Weickmann K, Zhang C, Donner L, Gottschalck J, Higgins W, Kang I-S, Legler D, Moncrieff M, Schubert S, Stern W, Vitart F, Wang B, Wang W, Woolnough S. 2009. MJO simulation diagnostics. J. Climate 22: 3006-3030, doi: http://dx.doi.org/10.1175/2008JCLI2731.1.

Walters DN, Best MJ, Bushell AC, Copsey D, Edwards JM, Falloon PD, Harris CM, Lock AP, Manners JC, Morcrette CJ, Roberts MJ, Stratton RA, Webster S, Wilkinson JM, Willett MR, Boutle IA, Earnshaw PD, Hill PG, MacLachlan C, Martin GM, Moufouma-Okia W, Palmer MD, Petch JC, Rooney GG, Scaife AA, Williams KD. 2011. The Met Office Unified Model Global Atmosphere 3.0/3.1 and JULES Global Land 3.0/3.1 configurations. Geosci. Model Dev. 4: 919-941, doi: 10.5194/gmd-4-919-2011.

Weisheimer A, Palmer TN, Doblas-Reyes FJ. 2011. Assessment of representations of model uncertainty in monthly and seasonal forecast ensembles. Geophys. Res. Lett. 38: L16703, doi: 10.1029/2011GL048123.

Wheeler M, Kiladis GN. 1999. Convectively coupled equatorial waves: Analysis of clouds and temperature in the wavenumber-frequency domain. J. Atmos. Sci. 56: 374-399, doi: http://dx.doi.org/10.1175/1520-0469(1999) $056<0374$ :CCEWAO > 2.0.CO;2.

Wielicki BA, Barkstrom BR, Harrison EF, Lee RB, Smith GL, Cooper JE. 1996. Clouds and the Earth's radiant energy system (CERES): an earth observing system experiment. Bull. Am. Meteorol. Soc. 77: 853-868.

Williams PD. 2005. Modelling climate change: The role of unresolved processes. Philos. Trans. R. Soc. London, Ser. A 363: 2931-2946, doi: 10.1098/rsta.2005. 1676.

Williams PD. 2012. Climatic impacts of stochastic fluctuations in air-sea fluxes. Geophys. Res. Lett. 39: L10705, doi: 10.1029/2012GL051813.

Wood N, Staniforth A, White W, Allen T, Diamantakis M, Gross M, Melvin T, Smith C, Vosper S, Zerroukat M, Thuburn J. 2013. An inherently mass-conserving semi-implicit semi-Lagrangian discretisation of the deepatmosphere global nonhydrostatic equations. To appear in Q. J. R. Meteorol. Soc., doi: 10.1002/qj.2235.

Zhang C. 2005. Madden-Julian Oscillation. Rev. Geophys. 43: RG2003, doi: 10.1029/2004RG000158. 